\title{
A Data-Driven Analytical Approach to Enable Optimal Emerging Technologies Integration in the Co-Optimized Electricity and Ancillary Service Markets
}

\author{
Yang Chen ${ }^{\mathrm{a}}$, Mengqi Hu, ${ }^{\mathrm{a},}$, and Zhi Zhou ${ }^{\mathrm{b}}$ \\ ${ }^{a}$ Department of Mechanical and Industrial Engineering, University of Illinois at Chicago, 842 W. Taylor \\ Street, 3023 ERF, Chicago, IL 60607 \\ ${ }^{\mathrm{b}}$ Energy Systems Division, Argonne National Laboratory, 9700 South Cass Avenue, Building 362, \\ Argonne, IL 60439 \\ *Corresponding author: Email address: mhu@uic.edu, Phone number: 312-413-7560
}

\begin{abstract}
The three emerging technologies (renewable energy, energy storage and demand response) play important roles in the co-optimized electricity and ancillary service (EAS) markets where electricity and ancillary service are simultaneously dispatched. While promising, we notice that most literature focuses on either technology integration or operation in the EAS markets. In this research, we develop a three-stage data-driven multi-criteria analytical framework to enable the optimal integration of emerging technologies and operation decisions in an EAS market context under various conditions. We propose multiple performance metrics to evaluate the EAS markets and use a Latin hypercube sampling approach to generate training data for these metrics based on a mixed integer quadratic programming model. Various data-driven models are developed for the performance metrics using the training data and two multi-criteria decision models based on the data-driven models are developed to select optimal technologies based on various criteria. To demonstrate the effectiveness of the proposed framework, we study a revised IEEE 118-bus system. It is demonstrated that our proposed approach can: 1) characterize the relations between each performance metric and technology parameters, 2) determine the significant impact technologies for each performance metric, and 3) recommend optimal emerging technologies integration for market/system operators.
\end{abstract}

Key words: Data-Driven Modeling; Multi-Criteria Decision; Electricity and Ancillary Service Market; Energy Storage System; Demand Response; Co-Optimization 


\section{Introduction}

American electricity demand is projected to increase $0.9 \%$ each year, from 3,839 billion $\mathrm{kWh}$ in 2011 to 4,930 billion $\mathrm{kWh}$ in 2040 [1]. In the United States, most of the power grid infrastructures were built in the 1930s [2]. In the past 40 years, five massive blackouts have occurred due to aging and overburdened power grids [3]. Faced with rising electricity demand, an aging existing infrastructure and uncertain energy future, several emerging technologies - renewable energy, energy storage system, and demand response program have been promoted. Renewable energy (e.g., solar and wind energy) is able to significantly reduce the carbon emission and operational cost. The energy demand can be shifted from peak period to off-peak period using the energy storage system. The demand response program aims to provide incentive for energy consumers to change their energy usage and reduce energy cost. These emerging technologies pose significant challenges to the technology integration and operation for the cooptimized electricity and ancillary service (EAS) markets where electricity and ancillary service are simultaneously dispatched.

It was demonstrated that renewable energy can play an important role in the EAS markets, and it is very challenging for system planners and operators to efficiently utilize renewable energy due to its intermittency [4-7]. For example, the average market price and price volatility are increased when more photovoltaics are adopted. The market configurations should be continuously improved to deal with high penetration of wind power in an effective way [7]. To improve the reliability, security and efficiency of current power system which allows larger penetration of renewable energy, the energy storage system has attracted great attentions during the last decades [8-10]. For example, the electric vehicle can be considered as a mobile energy storage to decrease carbon emissions and increase the integration level of renewable energy with the power grid [8]. The energy storage system can significantly influence the EAS markets by adaptively changing its charging/discharging strategy [11-14] since it cannot only play as additional loads but also fast-response power sources to provide energy and operating reserves. Demand response is another technology advancement to improve the reliability and efficiency of the power system [15-17]. The impacts of demand response on the EAS markets have been extensively studied in the existing literature [18-20], such as diverse pricing strategies [21,22], advanced metering [23,24], and customer behavior [25].

In the past few decades, extensive research has been conducted to develop efficient technology integration and/or operation decisions for the co-optimized EAS markets. The technology integration focuses on selecting appropriate technologies to optimize the EAS market performance (e.g., minimizing 
system cost, minimizing carbon emission, etc.). Given the integrated technologies, an efficient operation strategy can be developed to optimally operate the EAS markets.

The maximum integration of wind power can be up to 6,000 MW for the power system of Ireland based on the results from a stochastic mixed integer linear optimization model [26]. The potential cost of using wind power to reduce carbon dioxide emissions can be estimated using a comprehensive study conducted in [27] which explores the effects of production tax credits, renewable energy credits, wind and demand correlation, and carbon prices to the electricity market. It is shown that optimally deploying the energy storage system in the electricity market can reduce electricity price and production cost [28], and the system efficiency and security can be enhanced by involving large fleets of electric vehicles in the power system [29]. A study of fourteen different energy storage system technologies in seven real-time markets in the U.S. shows that the optimal configuration of the energy storage system highly depends on its technological characteristics [30]. The optimal sizing and siting decisions of the energy storage system are obtained using a cost-benefit analysis approach [31], and the results based on a modified IEEE 15-bus distribution network show that the capacity requirement of energy storage system can be reduced and the operational risk can be mitigated. It is suggested that deploying storage technologies can receive additional revenue streams which can be improved with high penetration of renewable energy [32]. A sizing algorithm is proposed for pumped hydro storage system by considering wind power penetration ability to the local grid [33]. Cost-based formulation is presented with some restrictions to determine the optimal size of battery in the operation management of a micro-grid [34]. A study on the profitability analysis of photovoltaic attached storage for a wholesale power market suggests that the optimum size of storage device should not exceed 5-hour of discharge at full power and the power can be limited to $40 \%$ of the nominal photovoltaic capacity [35]. A stochastic mixed integer programming model for hybrid power system design problem is developed for remote areas and a more efficient Benders decomposition algorithm with additional Pareto-optimal cuts is proposed to minimize the sum of purchased costs and expected operating costs over a given planning horizon [36]. An incentive demand response program based market is studied to identify an appropriate demand response program to improve load profile characteristics and customers satisfaction [16]. To find optimal values of incentive-based demand response programs, a multi-objective optimization model is proposed in [37] where demand response scheduling is performed simultaneously with the energy dispatch of generation and storage units. A simulation tool is developed to evaluate various micro-grid configurations under different scenarios to find cost effective design decisions [38]. A particle swarm optimization based approach is proposed for optimal design of hybrid renewable energy systems including generators and storage devices, where epsilon-constraint method is employed to minimize total cost, unmet load and fuel emission [39]. A genetic algorithm based method is utilized to solve a sizing optimization problem of a stand-alone micro- 
grid with multiple objectives including minimization of life cycle cost, maximization of renewable energy source penetration and minimization of pollutant emissions [40]. Components sizing algorithm for a hybrid energy system including diesel generator, photovoltaic panels and battery bank is proposed to minimize the total energy cost in [41].

Other than studying optimal technology integrations, extensive research has been conducted to optimally operate integrated emerging technologies in the EAS markets. A co-optimized dispatch model for the compressed air energy storage (CAES) is developed in [11] to determine optimal operation strategy and quantify net revenues of CAES and additional value to provide operating reserves. Hotelling rule is applied in [42] to determine a strategy for maximizing the values of battery system in South Korea's electricity market. A backwards induction approach is proposed in [43] to obtain optimal operation strategies of the energy storage system to actively participate in the EAS markets. The electricity market with wind energy and energy storage system can be optimally operated using a dynamic programming algorithm [44]. A stochastic programming based self-scheduling approach is developed to increase the profits of wind energy in an EAS market with pumped-storage plants [45]. Demand response simulator Demsi is used to study demand response actions and schemes in a distribution network, and a non-linear programming approach is used to determine optimal demand response solutions [21]. To respond to the dynamic energy prices, a robust linear programming model is proposed in [46] to maximize consumer utility by hourly adjusting the load levels. A set of demand response enabled load models at appliance levels are presented in [47] to study the household and distribution level energy consumption behavior changes. It is demonstrated that more than $75 \%$ of substantive costs imposed by wind uncertainty can be eliminated if the loads respond to these uncertainties immediately, and nearly $72 \%$ of this value will be cut if there is a 30-mins response lag [48]. The dispatchable demand combined with probabilistic wind power forecasting can help accommodate large shares of wind power in the operation of day-ahead and real-time electricity markets [49].

While promising, we notice that most literature focuses on either emerging technology integrations or operation decisions for given technologies. Considering the EAS market as an integrated system, studying the interactions between technology integration and operation is necessary. Second, even though there exists research exploring optimal technology integrations for the EAS markets, a majority of the research focuses on selecting an optimal/near-optimal technology integration plan from a limited number of plans based on single criterion (e.g., system cost). A more effective EAS market can be realized if more plans to be considered and more facets (e.g., cost, carbon emission) to be explored in the decision process. However, it will be challenging to use the operation decision model to evaluate the performance of a large number of integration plans from different perspectives. 
To address these research challenges, we develop a modeling framework to study the co-optimized EAS markets with various emerging technologies, such as renewable energy, energy storage system and demand response. The mixed integer quadratic programming (MIQP) model developed in our previous study [49] is extended to obtain operation decisions for the emerging technologies in the co-optimized EAS markets. Several quantitative metrics (e.g., total system operating cost, total carbon emissions, prices for electricity and ancillary service, etc.) are proposed to evaluate the performance of EAS markets from various perspectives. It is noted that evaluating the EAS markets with extensive integration plans using the operation decision models is computationally expensive. To overcome these issues, we develop computationally efficient data-driven models (a.k.a. meta-models) to replace these expensive models, and a multi-criteria analytical framework based on these data-driven models is developed to study optimal technology integration and operation in the EAS market. To this end, a three-stage analytical framework is developed to enable optimal integration of emerging technologies and operation decisions in an EAS market context under various conditions where stages I and II focus on data collection and data-driven model development and stage III is to develop multi-criteria decision models and solution approaches.

The proposed three-stage framework includes: 1) Stage I - Training data collection: A sample data of different technology integration plans (e.g., capacities of renewable energy and energy storage system, percentages of dispatchable demand) is generated using a Latin hypercube sampling (LHS) approach. The MIQP operation decision model is called to generate response data of the performance metrics for each sampled integration plan. 2) Stage II - Data-driven model development: Various data-driven models are developed for each performance metric to build the relations between the technology parameters and the system performance. The best data-driven model for each performance metric is selected using a crossvalidation approach. 3) Stage III - Multi-criteria decision model development: Two multi-criteria decision models are developed to obtain optimal technology integration decisions using the data-driven models. The performance of the developed framework are tested using a revised IEEE 118-bus system. It is concluded from the experimental results that: 1) The developed data-driven models can characterize the relations between each performance metric and technology parameters, and determine the significant impact technologies for each performance metric. 2) The multi-criteria decision models are computationally efficient and flexible to recommend optimal integration decisions based on singlecriterion, bi-criteria, or many-criteria (more than two criteria).

In summary, the contributions of this research lie in three aspects: 1) A multi-criteria data-driven approach is developed to study optimal technology integration and operation decisions in the cooptimized EAS markets. This approach can enable flexible integration decisions based on various criteria and allow us to design cost effective and environmental sustainable EAS markets. 2) Several data-driven models are developed to characterize various performance metrics which can provide useful information 
to discover the relations between technology parameters and system performance. 3) A computationally efficient analytical tool is developed for market/system operators to redesign the existing power system by optimally integrating emerging technologies for energy efficiency and sustainability.

This paper is organized as follows: Section 2 briefly introduces the modeling framework of the cooptimized EAS markets, followed by detail description of the proposed data-driven analytical framework in Section 3. Section 4 presents the experimental analysis results. Finally, conclusions and future studies are discussed in Section 5.

\section{Modeling Framework for the Co-Optimized EAS Markets}

Based on our previous study in [49], we develop a modeling framework (see Figure 1) to study the day-ahead EAS markets with thermal generators, wind power, energy storage system and elastic demand response. In the proposed framework, traditional thermal generator and wind energy are considered as energy supply. Wind energy is treated as a zero operational cost energy source. To mitigate volatility and intermittency introduced by renewable energy, the energy storage systems are used. In this research, four kinds of operation reserve are considered: upward reserve (spinning up reserve, non-spinning up reserve) and downward reserve (spinning down reserve, non-spinning down reserve). Please note that we consider the non-spinning down reserve introduced in $[29,50]$ to keep the consistency and completeness. The traditional thermal generators and energy storage systems can provide these four operation reserve services $[29,50]$ by changing their operational states.

\section{[Insert Figure 1 Here]}

The state transition process and corresponding operation reserve capability in the process are illustrated in Figure 2. We model the capabilities of energy storage system to provide these four different operation reserves in three different operation modes (CHARGING, DISCHARGING, IDLE in Figure 2.

1) State of charging: When the energy storage system is charging, it's equivalent to electric load which requests energy from power grid. As a result, spinning down reserve can be provided by raising charging rate, and spinning up reserve is supplied if the charging rate is decreased.

2) State of discharging: spinning up reserve is provided through increasing discharging rate and spinning down reserve is provided by decreasing discharging rate.

3) State of idle: The energy storage system will have the capacity to transit into charging or discharging state, and non-spinning down reserve or non-spinning up reserve can be provided correspondingly.

In this research, the spinning up reserve can be sold as non-spinning up reserve in practical operation of reserve market. Therefore, we model the non-spinning up reserve provided by thermal generator unit as 
two parts: one part comes from the process of starting up (see variable unsrf in Appendix A) and the other part comes from the same process for spinning up reserve (see variable unsrn in Appendix A).

[Insert Figure 2 Here]

We extend the MIQP model developed in our previous research [49] to study the operation decisions of the co-optimized EAS markets. The objective is to minimize total system operating cost, including fuel cost and startup cost from thermal generators, penalty for unserved services from electricity and reserve market, and social utility of flexible response from demand side. As demonstrated in [49], the aggregate flexible demand is modeled as a linear demand curve, then the area under the demand curve which represents utility for flexible consumers is quadratic and added as a negative term to the objective function. Since social utility of flexible demand is subtracted from the total system operation cost, the objective function is equivalent to maximizing social surplus. We assume that operating reserves must be met by thermal generators. Additional reserves are carried to handle situations with over forecasting of wind power. All the system-wide and technical constraints for thermal generators are considered, including generation-load balance, spinning and non-spinning reserve requirements, startup/shutdown and minimum on/off time restriction, and ramp up/down limits. The detailed descriptions of the MIQP model are provided in Appendix A.

To evaluate the performance of the EAS markets from different perspectives, we develop a set of quantitative metrics as shown in Table 1. For demand response, the social surplus from dispatchable demand $(P D)$ is considered in the objective function, so $P D$ is not considered as an individual performance metric in this research.

[Insert Table 1 Here]

\section{Proposed Data-Driven Multi-Criteria Analytical Framework}

In this research, we develop a three-stage data-driven multi-criteria analytical framework (see Figure 3) for optimal technology integration and operation in the EAS markets.

- Stage I - Training Data Collection (see Section 3.1): A Latin hypercube sampling approach is employed to generate sample data on the technology integration decision space (e.g., wind power capacity, battery capacity, percentage of dispatchable demand). The MIQP model is used to obtain the values of our proposed quantitative performance metrics for each sampled integration plan.

- $\quad$ Stage II - Data-Driven Model Development (see Section 3.2): The training data generated from the MIQP model is used to generate various data-driven models for each performance metric, and the best data-driven model will be selected to represent each performance metric using a cross-validation approach. 
- Stage III - Multi-Criteria Decision Model Development (see Section 3.3): Two multi-criteria decision models are constructed using the data-driven models to obtain optimal technology integration decisions for the EAS markets.

\section{[Insert Figure 3 Here]}

\subsection{Stage I - Training Data Collection}

This stage includes two steps: 1) integration decision space sampling, and 2) training data generation. We use the LHS method to generate sample data on the technology integration decision space. LHS is a statistical sampling method commonly used in construction of computer experiments due to its good uniformity and coverage from a multidimensional distribution, and its sample size is not strictly determined by the number of dimensions of the simulation design space [51]. In this research, we consider various technology integration plans including different wind capacities (see parameter $W$ in Appendix A), battery capacities (see parameter EMAX in Appendix A), and percentages of dispatchable demand (see parameter 1-INELASTICRATIOM in Appendix A).

We will run the MIQP model (see Appendix A) on all the sample data using a MIQP solver in the CPLEX Optimization Studio (version 12.5.1) to get the values of the performance metrics (see Table 1). We employ the same procedure as defined in [52] to calculate the prices of electricity and reserves in three steps: 1) The MIQP problem is solved using the CPLEX solver. 2) An equivalent linear programming model is constructed by fixing all the integer/binary variables as their optimal values in the MIQP problem. 3) The linear programming model is solved and the dual variables of the constraints in Eqs. (7), (33)-(36) are considered as the prices of electricity and reserves.

\subsection{Stage II - Data-Driven Model Development}

We will focus on data-driven model (a.k.a. meta-model) development in this stage which can characterize the relations between technology parameters (e.g., wind capacity, battery capacity, percentage of dispatchable demand) and system performance (e.g., performance metrics in Table 1). The data-driven modeling process involves model fitting or function approximation to the sampled data of design variables and responses from the detailed model [53], and can be used to construct computationally efficient models to replace computationally expensive models. In this research, various data-driven models collected from [54] are studied, such as Kriging, radial basis function, etc. We will build multiple data-driven models for each performance metric, and select the best model based on an accuracy measure, normalized root mean square error.

To validate the performance of the data-driven models, we will use a cross-validation approach. The training data are equally partitioned into several complementary subsets, one subset is used as testing 
dataset and the remaining subsets are used as training dataset. Multiple rounds of cross-validation will be performed until we consider all the subsets as testing datasets. The mathematical formulations of the studied data-driven models and the cross-validation process can be found in our previous study [55,56].

\subsection{Stage III - Multi-Criteria Decision Model Development}

In this research, we develop two different models to study multi-criteria technology integration decisions for the EAS markets. The first model is a weighted sum approach based multi-objective optimization model to obtain Pareto optimal technology integration decisions due to its simplicity for implementation and good performance with small number of objectives. The first model is formulated as

$$
\begin{gathered}
\min \sum_{r=1}^{R} w_{r} f_{r}(\mathbf{x}) \\
\text { s.t. } \sum_{r=1}^{R} w_{r}=1, w_{r} \geq 0, \mathbf{x} \in S^{3}
\end{gathered}
$$

where $\mathbf{x}$ is the vector of decision variables which include wind capacity (see parameter $W$ in Appendix A), battery capacity (see parameter $E M A X$ in Appendix A), and percentage of dispatchable demand (see parameter 1-INELASTICRATIOM in Appendix A), $\mathrm{S}^{3}$ represents the feasible ranges for these three decision variables, $f_{r}(\mathbf{x})$ is the data-driven model for the performance metric $r, R$ is the total number of performance metrics in Table 1 which is 13 in this research, and $w_{r}$ is the weight for the performance metric $r$. In this research, we will adopt the GlobalSearch solver in MATLAB to solve the first model for a given weights combination. Enumerating all of the possible weights combinations in Eq. (1), we can generate a complete set of Pareto solutions. However, it will be computationally expensive when the number of objectives is increased.

The second model is based on the desirability function approach [57-59] which focuses more on large number of objectives. A value of desirability, $d_{r}$, is assigned to the performance metric $r$, and an overall desirability $D$ is defined to combine all the performance metrics using the weighted geometric mean. Different desirability functions are chosen depending on the optimization goal of different performance metrics. Desirability functions in Eqs. (2)-(3) are suited for preferences of "the smaller the better" (e.g., $C_{\text {total }}, E_{\text {carbon }}, P_{\text {energy }}, P_{d s r}, P_{u s r}, P_{d n s r}, P_{\text {uns }}, N_{c t d}, N_{d t c}$ in Table 1) and "the larger the better" (e.g., $D_{\text {char }}, D_{d c h a r}$, $V_{\text {batt }}, R_{\text {wind }}$ in Table 1$)$ respectively.

$$
\begin{aligned}
& d_{r}\left(f_{r}(\mathbf{x})\right)=\left\{\begin{array}{cc}
1, & \text { if } f_{r}(\mathbf{x}) \leq l_{r} \\
\left|\frac{f_{r}(\mathbf{x})-u_{r}}{l_{r}-u_{r}}\right|^{\alpha}, & \text { if } l_{r}<f_{r}(\mathbf{x})<u_{r} \\
0, & \text { if } f_{r}(\mathbf{x}) \geq u_{r}
\end{array}\right. \\
& d_{r}\left(f_{r}(\mathbf{x})\right)=\left\{\begin{array}{cc}
0, & \text { if } f_{r}(\mathbf{x}) \leq l_{r} \\
\left|\frac{f_{r}(\mathbf{x})-l_{r}}{u_{r}-l_{r}}\right|^{\alpha}, & \text { if } l_{r}<f_{r}(\mathbf{x})<u_{r} \\
1, & \text { if } f_{r}(\mathbf{x}) \geq u_{r}
\end{array}\right.
\end{aligned}
$$


where $l_{r}$ is the minimum acceptable value of the performance metric $r, u_{r}$ is the highest value of performance metric $r, \alpha$ is a user specified value which reflects the scale level. The second model can be formulated as

$$
\begin{gathered}
\max \left[\prod_{r=1}^{R} w_{r} d_{r}\left(f_{r}(\mathbf{x})\right)\right]^{1 / \sum_{r=1}^{R} w_{r}} \\
\text { s.t. } w_{r} \geq 0, \mathbf{x} \in S^{3}
\end{gathered}
$$

We use a general nonlinear solver BARON to solve the second model.

\section{Experimental Analysis}

In this section, four sets of experiments are studied to evaluate the performance of the data-driven multi-criteria analytical framework proposed in Section 3. In the first set of experiments, the performance of data-driven models for various metrics are evaluated, and the best data-driven model for each performance metric is selected. The last three sets of experiments focus on single-criterion, bi-criteria, and many-criteria technology integration decisions using our proposed framework.

In this research, the parameters of thermal generators are based on the IEEE 118-bus data [60] which includes 54 thermal generating units (total capacity: 7,220 MW). Carbon intensity data for the IEEE 118bus system is adopted from [61,62]. The number of batteries is set to be 6 with same technical specifications. Hourly wind power production profile (in the form of capacity factor) and load profile are scaled based on the real data from Colorado Spring in July 2006.

A monthly load and wind production data set is used in this research (see Figure 4). The hourly price of electricity can be obtained as the dual value of corresponding load balance constraint (see Table 1). In this research, we calculate the hourly price of electricity over one month, and determine the price of electricity $\left(P_{\text {energy }}\right)$ as the average price over this month. The prices of four reserves are calculated in the same way. The EAS markets settings are the same as settings in [49]. In our previous study [63], the settings of reserve requirements can impact the system cost, prices of energy and reserve, and system reliability. In this research, we adopt the same approach studied in [63] to set the reserve requirements. The requirement of reserve includes: 1) base reserve associated with load (URB, UNRB, DRB, and DNRB), and 2) reserve used to mitigate variations of wind energy ( $U R W, U N R W, D R W$, and $D N R W$ ). The upward and downward base reserve associated with load are set as $11 \%$ and $1 \%$ of the load respectively. The reserve related to wind energy is dynamically calculated based on forecasted quantiles of wind power supply. Upward reserve requirement is determined by $50 \%-25 \%$ quantile of wind power supply which means this amount of upward reserve has to be dispatched to cover generation loss if wind energy goes down from expected value (50\%) to $25 \%$ quantile. On the other hand, downward reserve requirement is determined as $75 \%$ - 50\% quantile of wind power supply, which means this amount of downward reserve 
has to be dispatched to introduce additional wind power if wind goes up from expected value (50\%) to $75 \%$ quantile.

\section{[Insert Figure 4 Here]}

\subsection{Data-Driven Model Selection for Various Performance Metrics}

In this research, we set the ranges of the three technology parameters: 1) wind capacity as [0, $3,000 \mathrm{MW}], 2)$ battery capacity as [0,900MW], and 3) percentage of dispatchable demand as [0, 0.3] based on the demand and thermal generator capacities. The sample size of the Latin hypercube sampling is 300. The values of the performance metrics for these 300 sampling data will be obtained using the MIQP model. The significance test from the analysis of variance is provided in Table 2 and factors with p-values less than 0.05 are considered to be significant. In Table $2, F$ ratio is calculated as $M S_{\text {between }} /$ $M S_{\text {within }}$, where $M S_{\text {between }}$ is the variance between groups and $M S_{\text {within }}$ is the variance within groups. Given sample size $n$ and number of groups $k, M S_{\text {between }}=S S_{\text {between }} /(k-1), M S_{\text {within }}=S S_{\text {within }} /(n-k) \cdot p$-value gives probability of the $F$ ratio as large as what is observed and it can be obtained from $F$-distribution table after $F$ ratio is calculated. The top three most significant impact factors for each performance metric are highlighted with different colors (e.g., the significant effect will be demand response > wind > battery indicated by $F$ ratio for total $\left.\operatorname{cost} C_{\text {total }}\right)$. As demonstrated from $F$ ratio in Table 2, demand response is the most significant impact factor on total operating cost reduction while battery capacity has relatively moderate effect. This can also be proved in the objective function (see Eq. (5)) as the last term $P D$ is generated by demand response which is determined by total demand times percentage of dispatchable demand (see parameter 1-INELASTICRATIOM in Appendix A). Thus, demand response will have direct influence on total system operating cost metric. The effect on total cost from wind energy mainly reflects in cost saving of traditional generation units which is not as much as demand response but greater than battery capacity, however, wind capacity has the most significant effect on carbon emission.

\section{[Insert Table 2 Here]}

We will develop various data-driven models [54] using the 300 sample data, and validate each model using a cross-validation approach. 10-fold cross validation is applied with splitting 90\% samples as training subset and $10 \%$ as validation subset to prevent over-fitting. An accuracy measure, normalized root mean square error (NRMSE), is used to evaluate the performance of each data-driven model. It is observed from Table 3 that different performance metrics could be described by the best data-driven models with lowest accuracy error. In this research, we will implement the best model indicated by minimum NRMSE value (see bold value in Table 3) as the data-driven model for each performance metric. For example, KRIG, RBF and MIX-RcPc will be chosen as data driven models for total system operating $\operatorname{cost}\left(C_{\text {total }}\right)$, total carbon emission $\left(E_{\text {carbon }}\right)$ and price for electricity $\left(P_{\text {energy }}\right)$ respectively. 
[Insert Table 3 Here]

\subsection{Single-Criterion Technology Integration Decisions}

The data-driven model can be used to estimate the values of each performance metric on the whole technology integration decision space. Taking the total system operating cost as an example, a sliced response cube in 3D space is generated by best fitted model KRIG from Table 3 and shown in Figure 5 a). As it can be seen, all three technologies can decrease the total system operating cost. On the other hand, the demand response has significant impact on the total system operating cost (see Table 2), and total system operating cost will be at a relatively low level when the demand response level is greater than 0.25. However, range $[0.25,0.3]$ of the demand response level is too high for current practice. To increase the level of demand response, it will have to be combined with better price incentives for electricity consumers [49]. As shown in Table 2 and Figure 5 b) (generated by best fitted model RBF from Table 3), the total carbon emission significantly depends on the wind energy level.

[Insert Figure 5 Here]

Other than the total system operating cost and total carbon emission shown in Figure 5, the price of energy (Figure 6 a), generated by best fitted model MIX-RcPc from Table 3), price of spinning up reserve (Figure $6 \mathrm{~b}$ ), generated by best fitted model KRIG from Table 3), potential arbitrage value of battery (Figure $6 \mathrm{c}$ ), generated by best fitted model MIX-RcKgM from Table 3), and price of spinning down reserve (Figure $6 \mathrm{~d}$ ), generated by best fitted model KRIG from Table 3) are also presented here. It is demonstrated that the price of energy is decreased and spinning up/down reserve will be increased when the wind capacity is high, and the potential arbitrage value of battery depends on the wind energy and battery capacities. This is determined by the nature of fluctuation in wind energy, and battery system plays an important role to offset the volatility and absorb more wind energy. Comparing Figure 6 a) with d), the price of spinning down reserve is higher than the price of energy when the wind capacity is high. This difference can motivate the thermal generator units to sell more spinning down reserve for more profit when a system becomes more uncertain and demands more reserve capacity because of the integration of renewable energy. Please note the high spinning up reserve prices around the up corner in Figure $6 \mathrm{~b}$ ) are introduced by the computational accuracy which is defined as relative gap in CPLEX solver ( 0.01 is used in this research). Increasing the computational accuracy will decrease the spinning up reserve prices for this area.

\section{[Insert Figure 6 Here]}

The sliced response cubes in Figure 5 and Figure 6 can be used to determine the optimal technology integration decisions when single criterion is considered. We can also revise the first model in Eq. (1) for single-criterion integration decisions by setting the weight for the performance metric to be optimized as 
1 and the weights for other performance metrics as 0. Taking the total system operating cost as an example, the minimum total system operating cost is $-\$ 1.995 \times 10^{7}$ at the configuration settings of $3,000 \mathrm{MW}$ wind capacity, $900 \mathrm{MW}$ battery capacity and $30 \%$ of dispatchable demand (see point A in Figure 5). The minimum total carbon emission is $9.341 \times 10^{5}$ tons at the configuration settings of 3,000MW wind capacity, 756MW battery capacity and $0 \%$ of dispatchable demand (see point B in Figure $5)$.

\subsection{Bi-Criteria Technology Integration Decisions}

Two competitive objectives that are mainly studied in literatures of the EAS markets are total system operating cost and carbon emission. Since it is impossible to find a single solution which can optimize the two objectives simultaneously, the Pareto optimal solutions are usually preferred. In this set of experiments, we will employ the first model (see Eq. (1)) to obtain Pareto integration decisions. Given the responses of the two objectives (see Figure 5) from their data-driven models, a weighted sum formulation is employed to obtain the Pareto optimal solutions. In this experiment, the number of objectives $R$ is 2 (e.g., total system operating cost and total carbon emission). We enumerate all the possible combinations of weights for total system operating cost and total carbon emission from 0 to 1 with step size 0.002 to generate the Pareto frontier as shown in Figure 7. It is observed from Figure 7 (solution point A, solution clusters B and C), all the Pareto optimal solutions are obtained at 3,000MW wind energy capacity. It's necessary to point out the Pareto solutions locate on the plane $(3,000 \mathrm{MW}, 0 \sim 900 \mathrm{MW}, 0 \sim 0.3)$ in Figure 5 under the technology parameter range settings in this research. The Pareto solution $(3,000 \mathrm{MW}, 756 \mathrm{MW}$, $0)$ can minimize the total carbon emissions $\left(9.341 \times 10^{5}\right.$ tons), and the total system operating cost ($\left.\$ 1.995 \times 10^{7}\right)$ is minimized at the Pareto solution $(3,000 \mathrm{MW}, 900 \mathrm{MW}, 0.3)$. These results are consistent with the results from single-criterion analysis in Section 4.2.

\section{[Insert Figure 7 Here]}

\subsection{Multi-Criteria Technology Integration Decisions}

More than two objectives can be considered from different perspectives by different stakeholders when integrate emerging technologies in the EAS markets. Some objectives are byproducts from solving the original model, such as energy price and life span measures of battery, and cannot be formulated in advance. Therefore, traditional closed form optimization cannot be applied to include all the objectives simultaneously. In addition, relatively high computational cost makes it impractical to solve such multicriteria model.

The second model in Eq. (4) is employed to study the multi-criteria technology integration decisions. In order to highlight the most desirable parameter space area, $\alpha$ is given a very high value 20 here. When 
all the performance metrics are considered with same importance (weights equal to 1 for all metrics), or partial performance metrics are considered (total system operating cost, total carbon emission, energy of

price, potential arbitrage value of battery, utilization ratio of wind energy are given same weights 1 , the other metrics are not considered), the overall desirability are demonstrated in Figure 8 a) and b) separately.

[Insert Figure 8 Here]

As shown in Figure 8 a) and b), there are two areas with relatively high desirability on the surface of the integration decision space for both all metrics and partial metrics scenarios. Points A and B in these two figures are the most desirable configurations for these two scenarios. The desirability of each performance metric at point $\mathrm{A}$ and $\mathrm{B}$ (transformed into $\alpha=1$ ) are recorded in Table 4.

\section{[Insert Table 4 Here]}

Based on the results, a maximum desirability is obtained with 2,940 MW of wind energy capacity, 540 MW of battery capacity, and $23 \%$ of dispatchable demand for a power system with maximum power output of 7,220 MW from thermal generating units and average daily load of 4,200 MW by equally considering all the performance metrics.

\section{Discussion, Conclusions, and Future Study}

In this research, we propose a three-stage data-driven multi-criteria analytical framework to enable optimal emerging technologies (renewable energy, energy storage system and demand response) integration and operation decisions for the co-optimized EAS markets under various conditions. The first stage focuses on training data collection for the data-driven model development in the second stage. A Latin hypercube sampling approach is employed to generate sampling data for different integration decisions, and a mixed integer quadratic programming model is developed to obtain the response values of our proposed multiple performance metrics for each sampled integration plan. The second stage develops data-driven models using the training data to build relations between the emerging technology parameters and performance metrics and validates the data-driven models using a cross-validation approach. Two multi-criteria decision models based on the data-driven models are developed in the third stage to recommend best technology integration decisions based on our proposed performance metrics. The experimental results on a revised IEEE 118-bus system demonstrate that our proposed approach is computationally efficient and flexible to make integration decisions based on single-criterion, bi-criteria, or many-criteria (more than two criteria).

Our proposed approach can determine the significant impact factors (e.g., wind energy, energy storage system, demand response) for each performance metric. For example, the demand response is the most significant impact factor for the total system operating cost and the wind energy capacity is the most significant impact factor for the total carbon emission. This type of information can provide insights to 
encourage most efficient emerging technologies (e.g. renewable energy, energy storage, and demand response) for existing energy systems in a EAS market context with various conditions. For example, for the area with high wind energy (e.g., Chicago area), it is preferred to have large battery capacity and high percentage of dispatchable demand to reduce the total energy cost (see Figure 4 a)), and large battery capacity and low percentage of dispatchable demand to reduce the total carbon emission (see Figure $4 \mathrm{~b}$ )).

In the future study, we will improve the performance of the data-driven multi-criteria analytical framework in the following aspects: 1) investigating some advanced approaches [64-67] to quantify the requirements of operating reserve to mitigate the uncertainties in wind energy, 2) including more parameters in the data-driven models (e.g., total capacity for thermal generators, total energy load) to develop more comprehensive analytic tools, and 3) developing robust decision models to consider various uncertainties in renewable energy and load profile. To further test the effectiveness and scalability of the proposed approach, a large scale EAS market which has more emerging technologies will be studied.

\section{Appendix A}

We extend the mixed integer quadratic programming model developed in our previous research [49] to study the operation decisions of the co-optimized EAS markets. The objective is to minimize total system operating cost, including fuel cost and startup cost from thermal generators, penalty for unserved services from electricity and reserve market, and social utility of flexible response from demand side. All the system-wide and technical constraints for thermal generators are considered, including generationload balance, spinning and non-spinning reserve requirements, startup/shutdown and minimum on/off time restriction, and ramp up/down limits. All parameters and variables defined in the following mathematical model are summarized and explained as follows. All the parameters and variables are nonnegative.

\begin{tabular}{|c|c|c|c|}
\hline \multicolumn{4}{|l|}{ Indices } \\
\hline$i$ & Index for thermal generating units & $k$ & Index for segment in linearized functions \\
\hline$j$ & Index for battery units & $t$ & Index for time (hour) \\
\hline \multicolumn{4}{|c|}{ Variables } \\
\hline \multicolumn{4}{|c|}{ - $\quad$ Variables for traditional generating units: } \\
\hline$p_{t, i}$ & Electricity generation, unit $i$, hour $t$ & $u_{s r u}$ & Spinning up reserve provided by unit $i$, hour $t$ \\
\hline delta $_{t, i, k}$ & The output on segment $k$ of generation unit $i$, hour $t$ & unsrn $_{t, i}$ & Non-spinning up reserve provided by online unit $i$, hour $t$ \\
\hline $\operatorname{pgmax}_{t, i}$ & Max available capacity, unit $i$, hour $t$ & $u n s r f_{t, i}$ & Non-spinning up reserve provided by offline unit $i$, hour $t$ \\
\hline $\operatorname{pgmin}_{t, i}$ & Min available capacity, unit $i$, hour $t$ & $d s r u_{t, i}$ & Spinning down reserve provided by unit $i$, hour $t$ \\
\hline$u_{t, i}$ & Commitment variable, unit $i$, hour $t$ & $d n s r u_{t, i}$ & Non-spinning down reserve provided by unit $i$, hour $t$ \\
\hline$y_{t, i}$ & Shut-down variable, unit $i$, hour $t$ & $z_{t, i}$ & Start-up variable, unit $i$, hour $t$ \\
\hline - $\quad \mathbf{V}$ & eries: & & \\
\hline$p c_{t, j}$ & Charging rate, batter $j$, hour $t$ & $s c_{t, j}$ & State of charging, battery $j$, hour $t$ \\
\hline
\end{tabular}




\begin{tabular}{|c|c|c|c|}
\hline $\operatorname{pcmax}_{t, j}$ & Maximum available charging rate, batter $j$, hour $t$ & $s d_{t, j}$ & State of discharging, battery $j$, hour $t$ \\
\hline $\operatorname{pcmin}_{t, j}$ & Minimum allowable charging rate, batter $j$, hour $t$ & $u s r b_{t, j}$ & Spinning up reserve provided by battery $j$, hour $t$ \\
\hline$p d_{t, j}$ & Discharging rate, batter $j$, hour $t$ & $u_{n s r b} b_{t, j}$ & Non-spinning up reserve provided by battery $j$, hour $t$ \\
\hline $\operatorname{pdmax}_{t, j}$ & Maximum available discharging rate, batter $j$, hour $t$ & $d s r b_{t, j}$ & Spinning down reserve provided by battery $j$, hour $t$ \\
\hline $\operatorname{pdmin}_{t, j}$ & Minimum allowable discharging rate, batter $j$, hour $t$ & $d n s r b_{t, j}$ & Non-spinning down reserve provided by battery $j$, hour $t$ \\
\hline \multicolumn{4}{|c|}{ - Variables for energy and reserve markets: } \\
\hline$d d_{t}$ & Dispatchable demand, hour $t$ & unsrns $_{t}$ & Non-spinning up reserve not served, hour $t$ \\
\hline$e^{e n s_{t}}$ & Amount of energy not served at hour $t$ & $d_{s r n s_{t}}$ & Spinning down reserve not served, hour $t$ \\
\hline$w g_{t}$ & Dispatched wind generation, hour $t$ & dnsrns $_{t}$ & Non-spinning down reserve not served, hour $t$ \\
\hline usrns $_{t}$ & Spinning up reserve not served, hour $t$ & & \\
\hline \multicolumn{4}{|l|}{$\underline{\text { Parameters }}$} \\
\hline \multicolumn{4}{|c|}{ - $\quad$ Parameters for traditional generating units: } \\
\hline$S C_{t, i}$ & Startup cost, unit $i$, hour $t$ & $U O_{i}$ & Initial state, unit $i$ \\
\hline$P O_{i}$ & Initial output, unit $i$ & $M B O N_{i}$ & Hours unit $i$ must be on from hour 1 \\
\hline$P R_{i, k}$ & Length of segment $k$, unit $i$ & $M B O F F_{i}$ & Hours unit $i$ must be off from hour 1 \\
\hline$P M A X_{i}$ & Maximum output, unit $i$ & $M C_{t, i, k}$ & Unit cost for segment $k$ of generation unit $i$, hour $t$ \\
\hline$P M I N_{i}$ & Minimum output, unit $i$ & $M U T_{i}$ & Min up time, unit $i$ \\
\hline$R D_{i}$ & Ramp down limit, unit $i$ & $M D T_{i}$ & Min down time, unit $i$ \\
\hline$R U_{i}$ & Ramp up limit, unit $i$ & $M U S R_{i}$ & Max upward spinning limit, unit $i$ \\
\hline$Q S C_{i}$ & Quick start capacity, unit $i$ & $M D S R_{i}$ & Max downward spinning limit, unit $i$ \\
\hline$R S U_{i}$ & Ramp startup limit, unit $i$ & $N L C_{t, i}$ & No load cost for generation unit $i$ at hour $t$ \\
\hline$R S D_{i}$ & Ramp shutdown limit, unit $i$ & $C B I_{i}$ & Carbon intensity for generation unit $i$ \\
\hline \multicolumn{4}{|c|}{ - $\quad$ Parameters for batteries: } \\
\hline$E_{j, t}$ & Stored energy, battery $j$, hour $t$ & $Q P C_{j}$ & Quick start charging rate, battery $j$ \\
\hline$E M A X_{j}$ & Maximum stored energy (Capacity), battery $j$ & $Q P D_{j}$ & Quick start discharging rate, battery $j$ \\
\hline $\operatorname{EMIN}_{j}$ & Minimum stored energy, battery $j$ & $P D M A X_{j}$ & Maximum discharging rate, battery $j$ \\
\hline$P C M A X_{j}$ & Maximum charging rate, battery $j$ & $\operatorname{PDMIN}_{j}$ & Minimum discharging rate, battery $j$ \\
\hline $\operatorname{PCMIN}_{j}$ & Minimum charging rate, battery $j$ & $J$ & Number of batteries \\
\hline \multicolumn{4}{|c|}{ - $\quad$ Parameters for energy markets: } \\
\hline$D_{t}$ & The amount of original load at hour $t$ & $U R B_{t}$ & Upward spinning base operating reserve, hour $t$ \\
\hline$C()$. & Penalty cost for reserve that not served & $U R W_{t}$ & Upward spinning wind operating reserve, hour $t$ \\
\hline$P D_{t}$ & Utility of elastic demand & $U N R B_{t}$ & Upward non-spinning base operating reserve, hour $t$ \\
\hline$W_{t}$ & Available wind generation, hour $t$ & $U N R W_{t}$ & Upward non-spinning wind operating reserve, hour $t$ \\
\hline$P_{r e f}$ & Reference price, elastic demand curve & $D R B_{t}$ & Downward spinning base operating reserve, hour $t$ \\
\hline ELASTICSLOPE & Slope of the elastic demand curve & $D R W_{t}$ & Downward spinning wind operating reserve, hour $t$ \\
\hline SRRESPONSETIME & Response time, spinning reserve & $D N R B_{t}$ & Downward non-spinning base operating reserve, hour $t$ \\
\hline NSRRESPONSETIME & Response time, non-spin reserve & $D N R W_{t}$ & Downward non-spinning wind operating reserve, hour $t$ \\
\hline INELASTICRATIOM & Ratio of inelastic demand & $T$ & Length of decision periods \\
\hline
\end{tabular}

\section{Objective Function:}

Min $\sum_{t, i, k}\left(M C_{t, i, k} \times\right.$ delta $\left._{t, i, k}\right)+\sum_{t, i}\left(S C_{t, i} \times z_{t, i}+N L C_{t, i} \times u_{t, i}\right)+\sum_{t} C\left(e n s_{t}\right) \times e n s_{t}+\sum_{t}\left[C\left(u s r n s_{t}\right) \times\right.$
usrns $_{t}+C\left(\right.$ unsrns $\left._{t}\right) \times$ unsrns $\left._{t}\right]+\sum_{t}\left[C\left(\right.\right.$ dsrns $\left._{t}\right) \times d s r n s_{t}+C\left(\right.$ dnsrns $\left.\left._{t}\right) \times d n s r n s_{t}\right]-\sum_{t} P D_{t}$ 
The objective is to minimize total system operating cost, including generation cost from thermal generators (the first two terms), penalty cost for unserved energy (the third term) and operating reserve (the fourth and fifth term), and utility of flexible demand (the last term), is calculated as below [49]:

$$
P D_{t}=\frac{P_{r e f} \times d d_{t}^{2}}{E L A S T I C S L O P E \times(1-I N E L A S T I C R A T I O M) \times D_{t} \times 2}-\frac{P_{\text {ref }}}{E \text { EASTICSLOPE }} \times d d_{t}+P_{\text {ref }} \times d d_{t}, \quad \forall t
$$

\section{Constraints:}

1) Load-generation balance

$$
\sum_{i} p_{t, i}+w g_{t}+e n s_{t}+\sum_{j} p d_{t, j}=d d_{t}+D_{t} \times I N E L A S T I C R A T I O M+\sum_{j} p c_{t, j} \quad \forall t
$$

2) Wind generation dispatch

$$
w g_{t} \leq W_{t} \quad \forall t
$$

3) Generation

$$
\begin{gathered}
p_{t, i}=\operatorname{PMIN}_{i} \times u_{t, i}+\sum_{k} \operatorname{delta}_{t, i, k} \quad \forall t, i \\
\operatorname{pgmin}_{t, i} \leq p_{t, i} \leq \operatorname{pgmax}_{t, i} \forall t, i \\
\operatorname{PMIN}_{i} \times u_{t, i} \leq \operatorname{pgmin}_{t, i} \leq P M A X_{i} \times u_{t, i} \quad \forall t, i
\end{gathered}
$$

4) Energy block

$$
\text { delta }_{t, i, k} \leq P R_{i, k} \forall t, i, k
$$

5) Battery constraints which are used to define battery's technique parameters include:

a) Maximum/minimum available charging and discharging rate constraints

$$
\begin{aligned}
\operatorname{pcmax}_{t, j} & \leq P C M A X_{j} \times s c_{t, j} \forall t, j \\
\operatorname{pcmin}_{t, j} & \geq P C M I N_{j} \times s c_{t, j} \forall t, j \\
\operatorname{pdmax}_{t, j} & \leq P D M A X_{j} \times s d_{t, j} \forall t, j \\
\operatorname{pdmin}_{t, j} & \geq P D M I N_{j} \times s d_{t, j} \forall t, j
\end{aligned}
$$

b) Actual charging/discharging rate constraints

$$
\begin{aligned}
& \operatorname{pcmin}_{t, j} \leq p c_{t, j} \leq \operatorname{pcmax}_{t, j} \forall t, j \\
& \operatorname{pdmin}_{t, j} \leq p d_{t, j} \leq \operatorname{pdmax}_{t, j} \forall t, j
\end{aligned}
$$

c) Capacity constraints

$$
\begin{gathered}
E_{j, t}=E_{j, t-1}+p c_{t, j}-p d_{t, j} \forall t, j \\
E M I N_{j} \leq E_{j, t} \leq E M A X_{j} \forall t, j
\end{gathered}
$$

d) States constraints: battery can only be in one of the three states (IDLE, CHARGING and DISCHARGING) at each time period.

$$
s c_{t, j}+s d_{t, j} \leq 1 \forall t, j
$$

6) Spinning and non-spinning reserve balance constraints include:

a) Reserve provided by thermal generators: the spinning up/down reserve are restricted by maximum 
spinning up/down reserve capacities of each generating unit. The spinning up/down reserve cannot be greater than the gaps between generation unit's maximum/minimum available power output capacity and its current power output. In addition, the non-spinning up/down reserve provided are limited by quick start capacity and ramp shutdown limits.

$$
\begin{aligned}
& \text { usru }_{t, i} \leq S R R E S P O N S E T I M E \times M U S R_{i} \times u_{t, i} \forall t, i \\
& \text { unsrn }_{t, i} \leq N S R R E S P O N S E T I M E \times \operatorname{MUSR}_{i} \times u_{t, i} \forall t, i \\
& \text { unsr }_{t, i} \leq N S R R E S P O N S E T I M E \times Q S C_{i} \times\left(1-u_{t, i}\right) \forall t, i \\
& \text { usru }_{t, i}+\text { unsrn }_{t, i} \leq \operatorname{pgmax}_{t, i}-p_{t, i} \forall t, i \\
& d s r u_{t, i} \leq \text { SRRESPONSETIME } \times \operatorname{MDSR}_{i} \times u_{t, i} \forall t, i \\
& \text { dnsru }_{t, i} \leq N S R R E S P O N S E T I M E \times M_{D S R} \times u_{t, i} \forall t, i \\
& d s r u_{t, i}+\operatorname{dnsru}_{t, i} \leq p_{t, i}-\operatorname{pgmin}_{t, i} \forall t, i
\end{aligned}
$$

b) Reserve provided by batteries: the spinning/non-spinning up reserve provided by battery under three different operation modes are expressed in Eqs. (29)-(30). The spinning/non-spinning down reserve are computed in Eqs. (31)-(32). Taking spinning/non-spinning up reserve as an example, 1) if battery is idle, the reserve provided by battery cannot be greater than its quick start discharging rate and available discharged energy, 2) if battery is charging, the reserve cannot be greater than the gaps between its charging rate and minimum charging rate, and 3) if battery is discharging, the reserve cannot be greater than the differences between its discharging rate and maximum discharging rate.

$$
\begin{aligned}
& u s r b_{t, j}+\operatorname{unsrb}_{t, j} \leq Q P D_{j} \times\left(1-s c_{t, j}-s d_{t, j}\right)+\left(p c_{t, j}-\operatorname{pcmin}_{t, j}\right)+\left(\operatorname{pdmax}_{t, j}-p d_{t, j}\right) \forall t, j \\
& u s r b_{t, j}+\operatorname{unsrb}_{t, j} \leq\left(E_{t, j}-E M I N_{j}\right)+\left(p c_{t, j}-\operatorname{pcmin}_{t, j}\right)+\left(p d \max _{t, j}-p d_{t, j}\right) \forall t, j \\
& d s r b_{t, j}+d n s r b_{t, j} \leq Q P C_{j} \times\left(1-s c_{t, j}-s d_{t, j}\right)+\left(\operatorname{pcmax}_{t, j}-p c_{t, j}\right)+\left(p d_{t, j}-p d \min _{t, j}\right) \forall t, j \\
& d s r b_{t, j}+\operatorname{dnsrb}_{t, j} \leq\left(\operatorname{EMAX}_{j}-E_{t, j}\right)+\left(\operatorname{prmax}_{t, j}-p c_{t, j}\right)+\left(p d_{t, j}-p d \min _{t, j}\right) \forall t, j
\end{aligned}
$$

c) Reserve requirements constraints

$$
\begin{gathered}
\sum_{i} d_{s r u_{t, i}}+\sum_{j} d s r b_{t, j}+d s r n s_{t} \geq D R B_{t}+D R W_{t} \forall t \\
\sum_{i} u_{s r u_{t, i}}+\sum_{j} u_{s r b_{t, j}}+\text { usrns }_{t} \geq U R B_{t}+U R W_{t} \forall t \\
\sum_{i} \text { dnsru }_{t, i}+\sum_{j} \text { dnsrb }_{t, j}+\text { dnsrns }_{t} \geq D N R B_{t}+D N R W_{t} \forall t \\
\sum_{i} \text { unsrf }_{t, i}+\sum_{i} \text { unsrn }_{t, i}+\sum_{j} \text { unsr }_{t, j}+\text { unsrns }_{t} \geq U N R B_{t}+U N R W_{t} \quad \forall t
\end{gathered}
$$

7) Shut down and start up

$$
\begin{gathered}
u_{t-1, i} \geq y_{t, i} \forall t, i, t \geq 2 \\
1-u_{t-1, i} \geq z_{t, i} \forall t, i, t \geq 2 \\
u_{t, i}-u_{t-1, i}=z_{t, i}-y_{t, i} \forall t, i, t \geq 2 \\
U O_{i} \geq y_{1, i} \forall i
\end{gathered}
$$




$$
\begin{gathered}
1-U O_{i} \geq z_{1, i} \forall i \\
u_{1, i}-U O_{i}=z_{1, i}-y_{1, i} \quad \forall i
\end{gathered}
$$

8) Minimum up and startup

$$
\begin{gathered}
u_{t, i}=1 \forall t, i, t \text { in } 1, \ldots, M B O N_{i} \\
u_{t, i} \geq z_{t p, i} \forall t, i, t p \text { in } t-M U T_{i}+1, \ldots, t, t p \geq 1 \\
u_{t, i} \geq \sum_{t p \text { in } t-M U T_{i}+1, \ldots, t, t p \geq 1} z_{t p, i} \forall t, i
\end{gathered}
$$

9) Minimum down and shutdown

$$
\begin{gathered}
u_{t, i}=0 \forall t, i, t \text { in } 1, \ldots, M B O F F_{i} \\
1-u_{t, i} \geq y_{t p, i} \forall t, i, t p \text { in } t-M D T_{i}+1, \ldots, t, t p \geq 1 \\
1-u_{t, i} \geq \sum_{t p \text { in } t-M D T_{i}+1, \ldots, t, t p \geq 1} y_{t p, i} \forall t, i
\end{gathered}
$$

10) Ramp up and ramp down

$$
\begin{gathered}
\operatorname{pgmax}_{t, i} \leq p_{t-1, i}+R U_{i} \times u_{t-1, i}+R S U_{i} \times z_{t, i} \forall t, i, t \geq 2 \\
\operatorname{pgmax}_{1, i} \leq P O_{i}+R U_{i} \times U O_{i}+R S U_{i} \times z_{1, i} \forall i \\
\operatorname{pgmin}_{t, i} \geq p_{t-1, i}-R D_{i} \times u_{t, i}-R S D_{i} \times y_{t, i} \forall t, i, t \geq 2 \\
\operatorname{pgmin}_{1, i} \geq P O_{i}-R D_{i} \times u_{1, i}-R S D_{i} \times y_{1, i} \forall i \\
\operatorname{pgmax}_{t-1, i} \leq P M A X_{i} \times u_{t, i}+R S D_{i} \times y_{t, i} \forall t, i, t \geq 2
\end{gathered}
$$

\section{Acknowledgement}

This research was supported by funds from the National Science Foundation award under grant number CMMI 1634738.

\section{References}

[1] Department of Energy. Annual Energy Outlook 2013 with Projections to 2040. 2013.

[2] Su W, Wang J. Energy Management Systems in Microgrid Operations. Electr J 2012;25:45-60. doi:http://dx.doi.org/10.1016/j.tej.2012.09.010.

[3] Farmer RG, Allen EH. Power System Dynamic Performance Advancement From History of North American Blackouts. IEEE Power Syst. Conf. Expo., 2006, p. 293-300. doi:10.1109/PSCE.2006.296322.

[4] Woo CK, Horowitz I, Moore J, Pacheco a. The impact of wind generation on the electricity spotmarket price level and variance: The Texas experience. Energy Policy 2011;39:3939-44. doi:10.1016/j.enpol.2011.03.084.

[5] Milstein I, Tishler A. Intermittently renewable energy, optimal capacity mix and prices in a deregulated electricity market. Energy Policy 2011;39:3922-7. doi:10.1016/j.enpol.2010.11.008.

[6] Brand B, Zingerle J. The renewable energy targets of the Maghreb countries: Impact on electricity supply and conventional power markets. Energy Policy 2011;39:4411-9. doi:10.1016/j.enpol.2010.10.010.

[7] Durrwachter H, Looney S. Integration of wind generation into the ERCOT market. IEEE Trans Sustain Energy 2012;3:862-7.

[8] Richardson DB. Electric vehicles and the electric grid: A review of modeling approaches, Impacts, 
and renewable energy integration. Renew Sustain Energy Rev 2013;19:247-54.

doi:10.1016/j.rser.2012.11.042.

[9] Koohi-Kamali S, Tyagi VV, Rahim N a., Panwar NL, Mokhlis H. Emergence of energy storage technologies as the solution for reliable operation of smart power systems: A review. Renew Sustain Energy Rev 2013;25:135-65. doi:10.1016/j.rser.2013.03.056.

[10] Ferreira HL, Garde R, Fulli G, Kling W, Lopes JP. Characterisation of electrical energy storage technologies. Energy 2013;53:288-98. doi:10.1016/j.energy.2013.02.037.

[11] Drury E, Denholm P, Sioshansi R. The value of compressed air energy storage in energy and reserve markets. Energy 2011;36:4959-73. doi:http://dx.doi.org/10.1016/j.energy.2011.05.041.

[12] Chen Y, Keyser M. Incorporating short-term stored energy resource into Midwest ISO energy and ancillary service market. IEEE Trans Power Syst 2011;26:829-38.

[13] Lefeng S, Qian Z, Yongjian P. The reserve trading model considering V2G Reverse. Energy 2013;59:50-5. doi:10.1016/j.energy.2013.07.030.

[14] Brekken T. Optimal energy storage sizing and control for wind power applications. IEEE Trans Sustain Energy 2011;2:69-77.

[15] Cappers P, Goldman C, Kathan D. Demand response in U.S. electricity markets: Empirical evidence. Energy 2010;35:1526-35. doi:10.1016/j.energy.2009.06.029.

[16] Aalami HA, Moghaddam MP, Yousefi GR. Demand response modeling considering Interruptible / Curtailable loads and capacity market programs. Appl Energy 2010;87:243-50. doi:10.1016/j.apenergy.2009.05.041.

[17] Albadi MH, El-Saadany EF. A summary of demand response in electricity markets. Electr Power Syst Res 2008;78:1989-96. doi:10.1016/j.epsr.2008.04.002.

[18] Kirschen D. Quantifying the Effect of Demand Response on Electricity Markets. IEEE Trans Power Syst 2009;24:1199-207. doi:10.1109/TPWRS.2009.2023259.

[19] Walawalkar R, Blumsack S, Apt J, Fernands S. An economic welfare analysis of demand response in the PJM electricity market. Energy Policy 2008;36:3692-702. doi:10.1016/j.enpol.2008.06.036.

[20] Gast N, Boudec J Le, Tomozei D. Impact of Demand-Response on the Efficiency and Prices in Real-Time Electricity Markets 2014;2.

[21] Faria P, Vale Z. Demand response in electrical energy supply: An optimal real time pricing approach. Energy 2011;36:5374-84. doi:http://dx.doi.org/10.1016/j.energy.2011.06.049.

[22] Lujano-Rojas JM, Monteiro C, Dufo-López R, Bernal-Agustín JL. Optimum residential load management strategy for real time pricing (RTP) demand response programs. Energy Policy 2012;45:671-9. doi:10.1016/j.enpol.2012.03.019.

[23] LeMay M, Nelli R, Gross G, Gunter C a. An Integrated Architecture for Demand Response Communications and Control. Proc 41st Annu Hawaii Int Conf Syst Sci (HICSS 2008) 2008:174174. doi:10.1109/HICSS.2008.60.

[24] Mak S. A synergistic approach to implement demand response, asset management and service reliability using smart metering, AMI and MDM systems. Power Energy Soc Gen Meet 2009 PES' 2009;63042:1-4.

[25] Kwag H-G, Kim J-O. Reliability modeling of demand response considering uncertainty of customer behavior. Appl Energy 2014;122:24-33. doi:10.1016/j.apenergy.2014.01.068.

[26] Meibom P, Barth R, Hasche B, Brand H, Weber C, O’Malley M. Stochastic Optimization Model to Study the Operational Impacts of High Wind Penetrations in Ireland. IEEE Trans Power Syst 2011;26:1367-79. doi:10.1109/TPWRS.2010.2070848.

[27] Baldick R. Wind and Energy Markets: A Case Study of Texas. IEEE Syst J 2012;6:27-34. doi:10.1109/JSYST.2011.2162798.

[28] Nyamdash B, Denny E. The impact of electricity storage on wholesale electricity prices. Energy Policy 2013;58:6-16. doi:10.1016/j.enpol.2012.11.033.

[29] Ortega-Vazquez M a., Bouffard F, Silva V. Electric Vehicle Aggregator/System Operator Coordination for Charging Scheduling and Services Procurement. IEEE Trans Power Syst 2013;28:1806-15. doi:10.1109/TPWRS.2012.2221750. 
[30] Bradbury K, Pratson L, Patiño-Echeverri D. Economic viability of energy storage systems based on price arbitrage potential in real-time U.S. electricity markets. Appl Energy 2014;114:512-9. doi:10.1016/j.apenergy.2013.10.010.

[31] Zheng Y, Dong ZY, Luo FJ, Meng K, Qiu J, Wong KP. Optimal allocation of energy storage system for risk mitigation of discos with high renewable penetrations. IEEE Trans Power Syst 2014;29:212-20. doi:10.1109/TPWRS.2013.2278850.

[32] McConnell D, Forcey T, Sandiford M. Estimating the value of electricity storage in an energyonly wholesale market. Appl Energy 2015;159:422-32. doi:10.1016/j.apenergy.2015.09.006.

[33] Kaldellis JK, Kapsali M, Kavadias KA. Energy balance analysis of wind-based pumped hydro storage systems in remote island electrical networks. Appl Energy 2010;87:2427-37. doi:10.1016/j.apenergy.2010.02.016.

[34] Bahmani-Firouzi B, Azizipanah-Abarghooee R. Optimal sizing of battery energy storage for micro-grid operation management using a new improved bat algorithm. Int J Electr Power Energy Syst 2014;56:42-54. doi:10.1016/j.ijepes.2013.10.019.

[35] Zucker A, Hinchliffe T. Optimum sizing of PV-attached electricity storage according to power market signals - A case study for Germany and Italy. Appl Energy 2014;127:141-55. doi:10.1016/j.apenergy.2014.04.038.

[36] Kuznia L, Zeng B, Centeno G, Miao Z. Stochastic optimization for power system configuration with renewable energy in remote areas. Ann Oper Res 2013;210:411-32. doi:10.1007/s10479-0121110-9.

[37] Fotouhi Ghazvini MA, Soares J, Horta N, Neves R, Castro R, Vale Z. A multi-objective model for scheduling of short-term incentive-based demand response programs offered by electricity retailers. Appl Energy 2015;151:102-18. doi:10.1016/j.apenergy.2015.04.067.

[38] Hafez O, Bhattacharya K. Optimal planning and design of a renewable energy based supply system for microgrids. Renew Energy 2012;45:7-15. doi:http://dx.doi.org/10.1016/j.renene.2012.01.087.

[39] Sharafi M, ELMekkawy TY. Multi-objective optimal design of hybrid renewable energy systems using PSO-simulation based approach. Renew Energy 2014;68:67-79. doi:10.1016/j.renene.2014.01.011.

[40] Zhao B, Zhang X, Li P, Wang K, Xue M, Wang C. Optimal sizing, operating strategy and operational experience of a stand-alone microgrid on Dongfushan Island. Appl Energy 2014;113:1656-66. doi:10.1016/j.apenergy.2013.09.015.

[41] Zhang X, Tan S-C, Li G, Li J, Feng Z. Components sizing of hybrid energy systems via the optimization of power dispatch simulations. Energy 2013;52:165-72. doi:10.1016/j.energy.2013.01.013.

[42] Shcherbakova A, Kleit A, Cho J. The value of energy storage in South Korea's electricity market: A Hotelling approach. Appl Energy 2014;125:93-102. doi:10.1016/j.apenergy.2014.03.046.

[43] Cho J, Kleit AN. Energy storage systems in energy and ancillary markets: A backwards induction approach. Appl Energy 2015;147:176-83. doi:10.1016/j.apenergy.2015.01.114.

[44] Dicorato M, Forte G, Pisani M, Member S, Trovato M. Planning and Operating Combined WindStorage System in Electricity Market. IEEE Trans Sustain Energy 2012;3:209-17.

[45] Varkani AK, Daraeepour A, Monsef H. A new self-scheduling strategy for integrated operation of wind and pumped-storage power plants in power markets. Appl Energy 2011;88:5002-12. doi:10.1016/j.apenergy.2011.06.043.

[46] Conejo AJ, Morales JM, Baringo L. Real-Time Demand Response Model. IEEE Trans Smart Grid 2010;1:236-42. doi:10.1109/TSG.2010.2078843.

[47] Shao S. Development of physical-based demand response-enabled residential load models. IEEE Trans Power Syst 2013;28:607-14.

[48] Madaeni S, Sioshansi R. Measuring the Benefits of Delayed Price-Responsive Demand in Reducing Wind-Uncertainty Costs 2013;28:4118-26.

[49] Botterud A, Zhou Z, Wang J, Sumaili J, Keko H, Mendes J, et al. Demand Dispatch and 
Probabilistic Wind Power Forecasting in Unit Commitment and Economic Dispatch: A Case Study of Illinois. IEEE Trans Sustain Energy 2013;4:250-61. doi:10.1109/TSTE.2012.2215631.

[50] Bouffard F, Galiana FD, Conejo AJ. Market-clearing with stochastic security-part I: formulation. IEEE Trans Power Syst 2005;20:1818-26. doi:10.1109/TPWRS.2005.857016.

[51] Zhang S, Zhu P, Chen W, Arendt P. Concurrent treatment of parametric uncertainty and metamodeling uncertainty in robust design. Struct Multidiscip Optim 2012;47:63-76. doi:10.1007/s00158-012-0805-5.

[52] O’Neill RP, Hedman KW, Krall EA, Papavasiliou A, Oren SS. Economic analysis of the N-1 reliable unit commitment and transmission switching problem using duality concepts. Energy Syst 2010;1:165-95. doi:10.1007/s12667-009-0005-6.

[53] Ryberg A, Bäckryd RD, Nilsson L. Metamodel-based multidisciplinary design optimization for automotive applications 2012.

[54] Juliane M. User guide for Modularized Surrogate Model Toolbox 2012:1-28.

[55] Cui C, Hu M, Weir JD, Wu T. A recommendation system for meta-modeling: A meta-learning based approach. Expert Syst Appl 2016;46:33-44. doi:http://dx.doi.org/10.1016/j.eswa.2015.10.021.

[56] Cui C, Wu T, Hu M, Weir JD, Li X. Short-term building energy model recommendation system: A meta-learning approach. Appl Energy 2016;172:251-63. doi:http://dx.doi.org/10.1016/j.apenergy.2016.03.112.

[57] John B. Application of desirability function for optimizing the performance characteristics of carbonitrided bushes. Int J Ind Eng Comput 2013;4:305-14. doi:10.5267/j.ijiec.2013.04.003.

[58] Kuhn M. The desirability Package 2012:1-17.

[59] Ozturk BA, Koksal G, Weber GW, Baron G. Optimization of desirability functions as a dnlp model by gams/baron n.d.

[60] JEAS_IEEE 118 bus 2004.

[61] Wang X, Gong Y, Jiang C. Regional Carbon Emission Management Based on Probabilistic Power Flow With Correlated Stochastic Variables. IEEE Trans Power Syst 2015;30:1094-103.

[62] Li B, Song Y, Hu Z. Carbon flow tracing method for assessment of demand side carbon emissions obligation. IEEE Trans Sustain Energy 2013;4:1100-7. doi:10.1109/TSTE.2013.2268642.

[63] Zhou Z, Botterud A. Dynamic Scheduling of Operating Reserves in Co-Optimized Electricity Markets With Wind Power. IEEE Trans Power Syst 2014;29:160-71. doi:10.1109/TPWRS.2013.2281504.

[64] Menemenlis N, Huneault M, Robitaille A. Computation of Dynamic Operating Balancing Reserve for Wind Power Integration for the Time-Horizon 1\&\#x2013;48 Hours. IEEE Trans Sustain Energy 2012;3:692-702. doi:10.1109/TSTE.2011.2181878.

[65] Holttinen H. Impact of hourly wind power variations on the system operation in the Nordic countries. Wind Energy 2005;8:197-218. doi:10.1002/we.143.

[66] Holttinen H, Milligan M, Kirby B, Acker T, Neimane V, Molinski T. Using Standard Deviation as a Measure of Increased Operational Reserve Requirement for Wind Power. Wind Eng 2008;32:355-77. doi:10.1260/0309-524X.32.4.355 .

[67] Black M, Strbac G. Value of Bulk Energy Storage for Managing Wind Power Fluctuations. IEEE Trans Energy Convers 2007;22:197-205. doi:10.1109/TEC.2006.889619. 


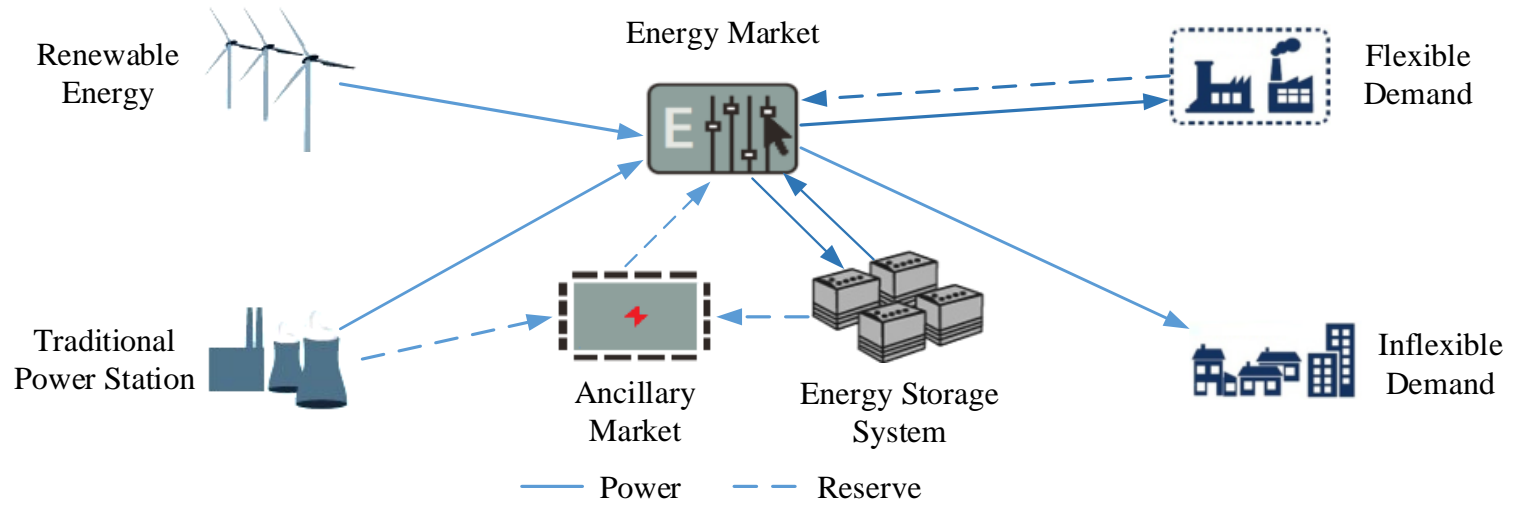

Figure 1 The modeling framework of co-optimized EAS markets 


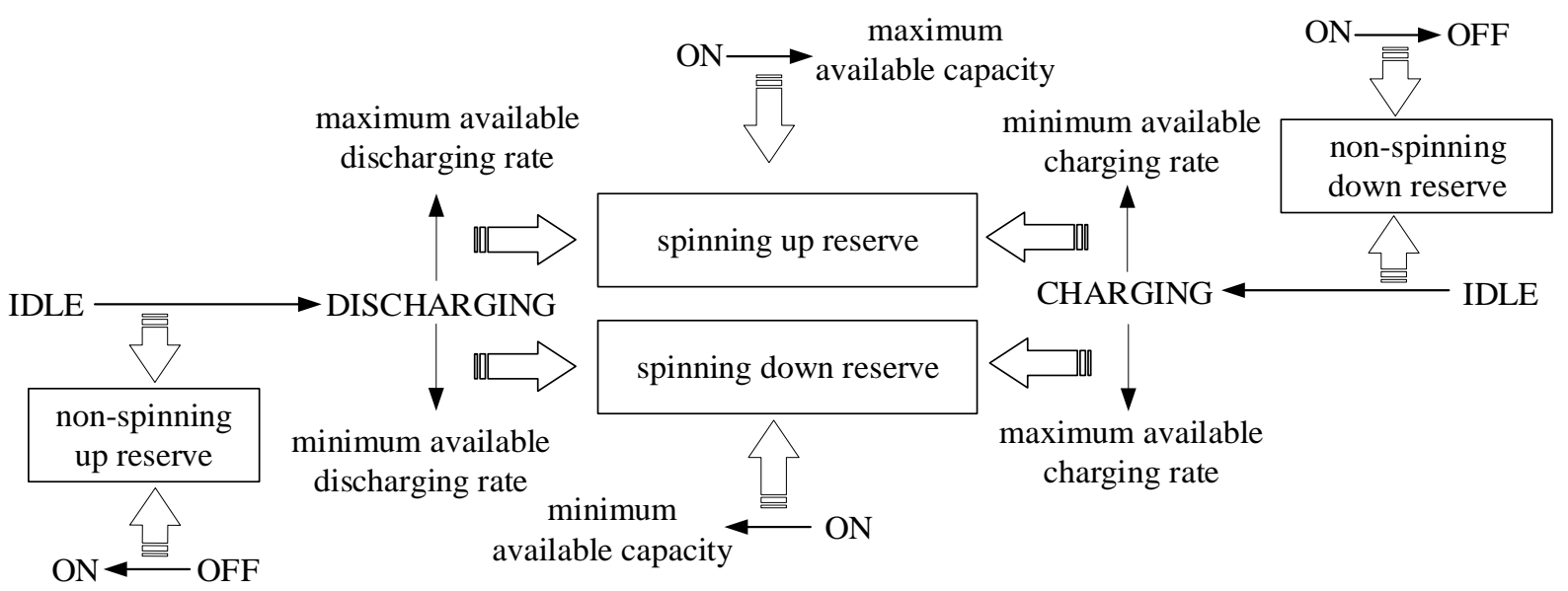

Figure 2 Reserves in all the state transition processes for traditional thermal generator (state: ON, OFF) and energy storage system (state: IDLE, CHARGING, DISCHARGING) 


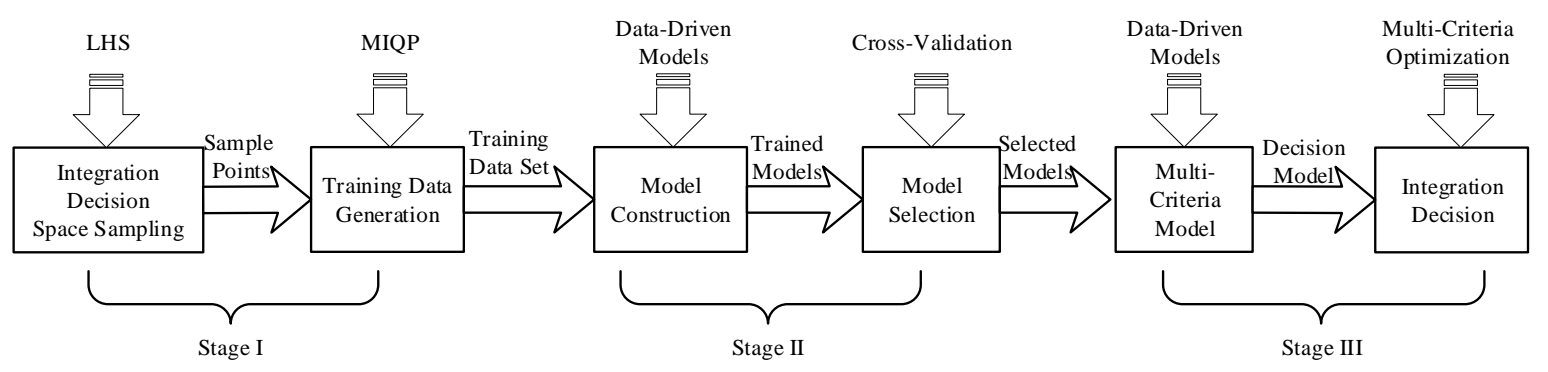

Figure 3 Three-stage data-driven multi-criteria analytical framework 


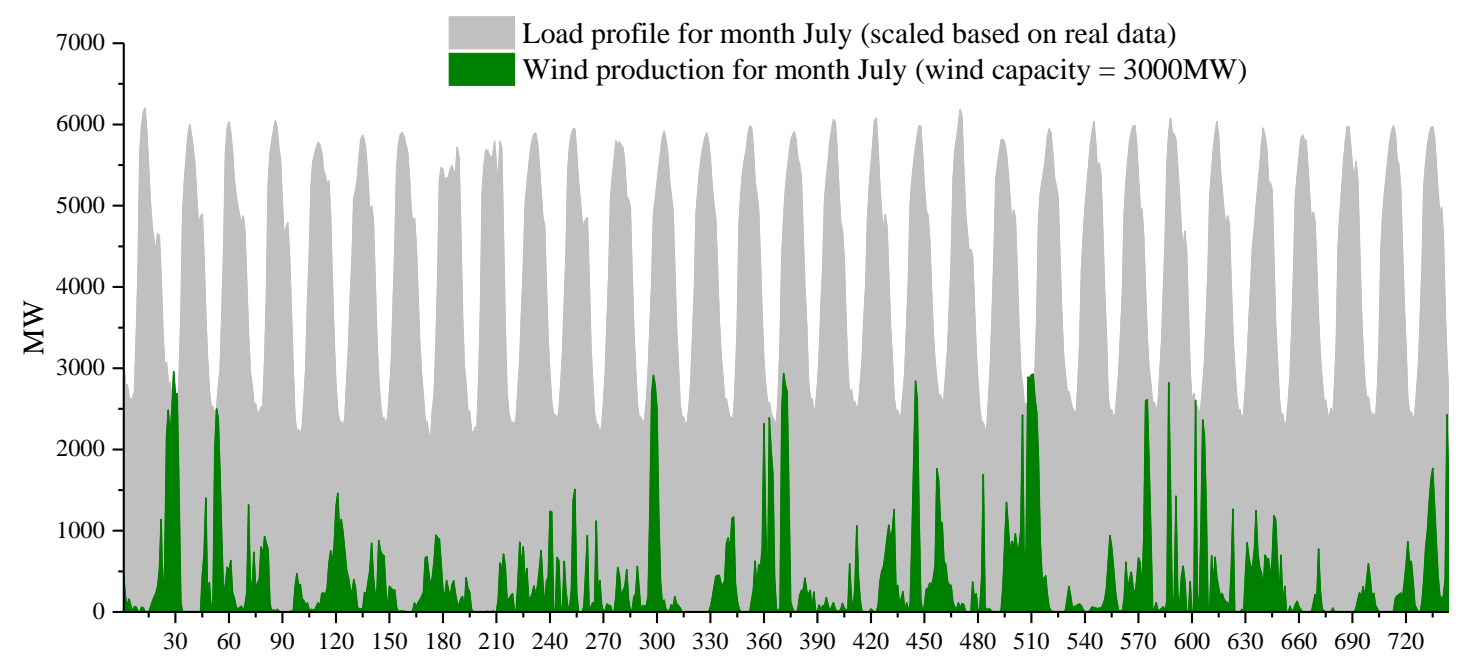

Hours for month July

Figure 4 Load profile and wind production for one month (July 2006) 


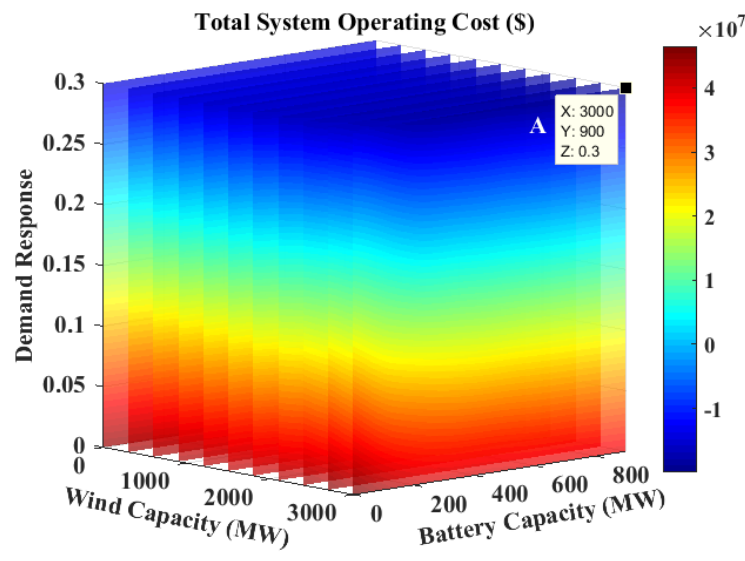

a)

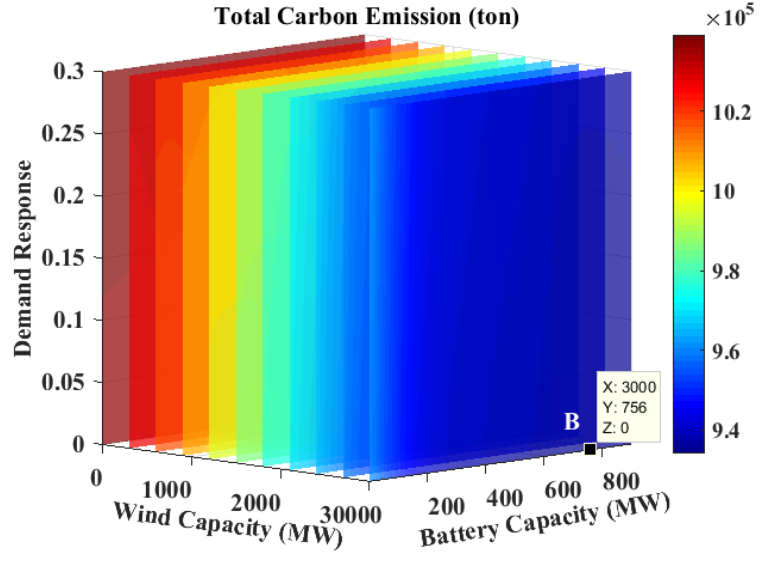

b)

Figure 5 a) sliced response cube for total system operating cost, b) sliced response cube for total carbon emission 


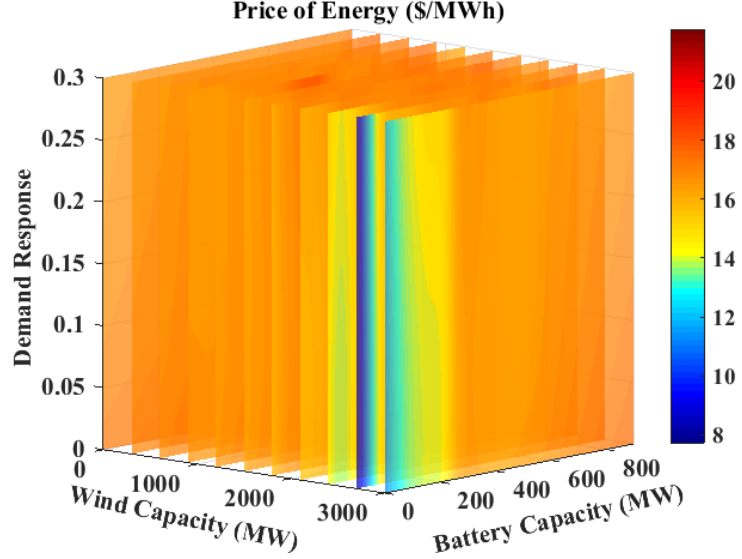

(a)

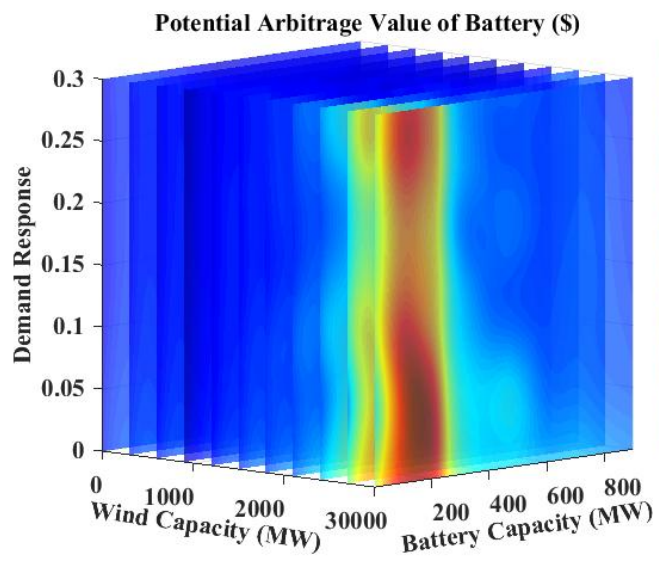

(c)

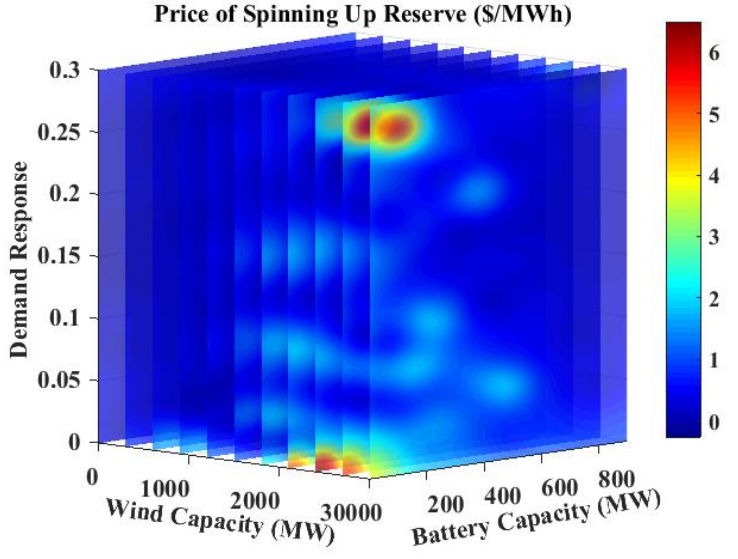

(b)
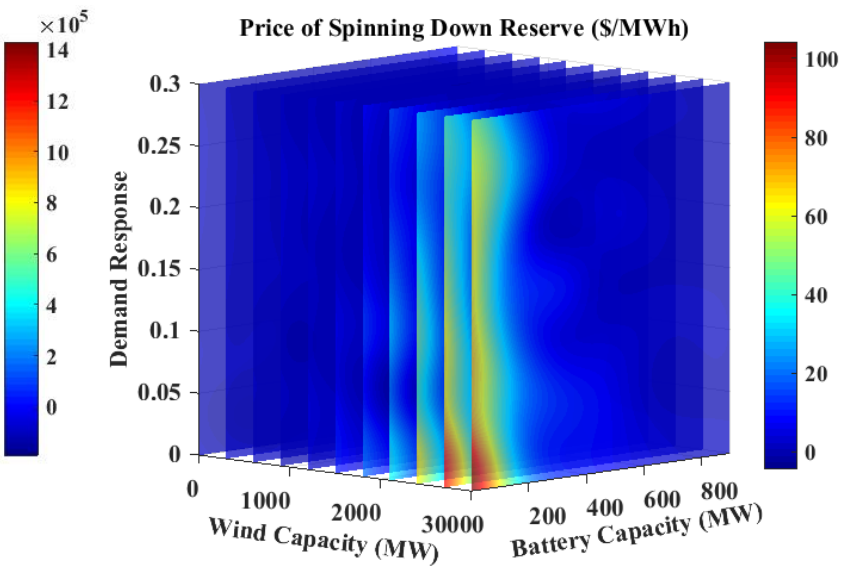

(d)

Figure 6 a) sliced response cube for price of energy, b) sliced response cube for price of spinning up reserve, c) sliced response cube for potential arbitrage value of battery, d) sliced response cube for utilization of wind energy 


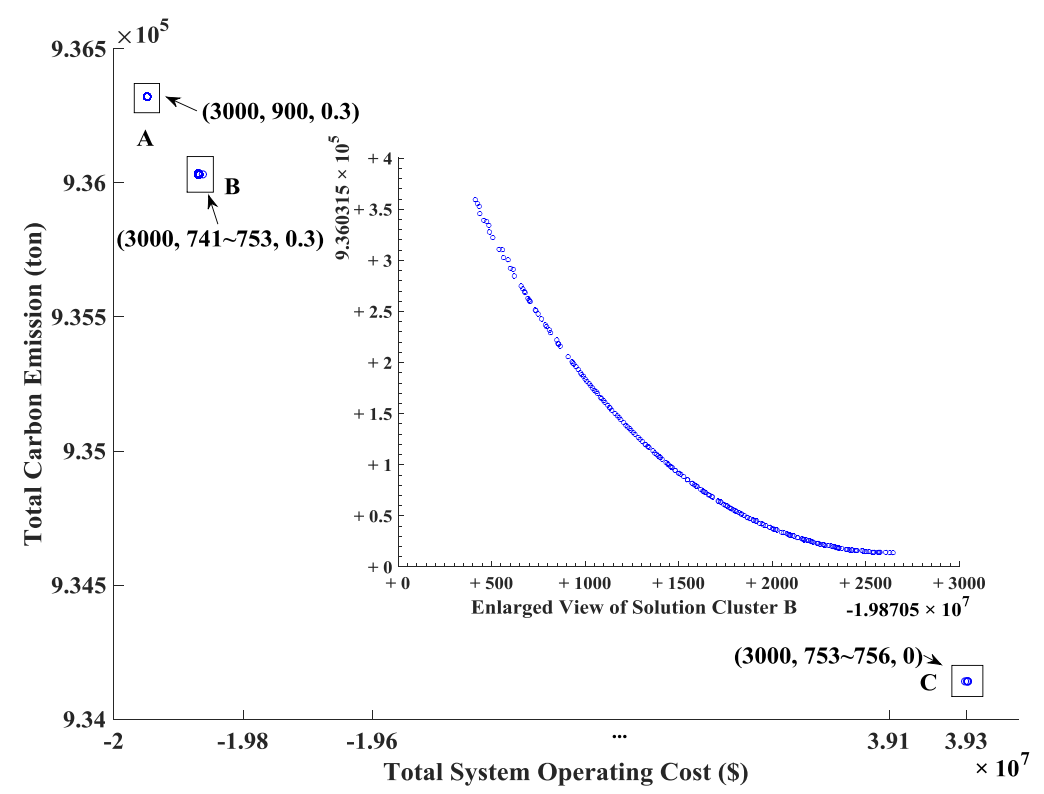

Figure 7 Pareto frontier of total system operating cost and total carbon emission 


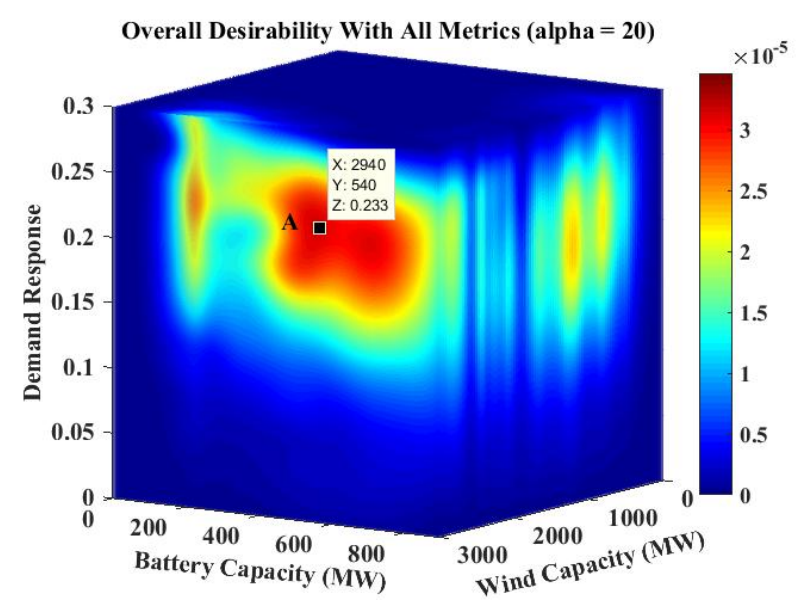

(a)

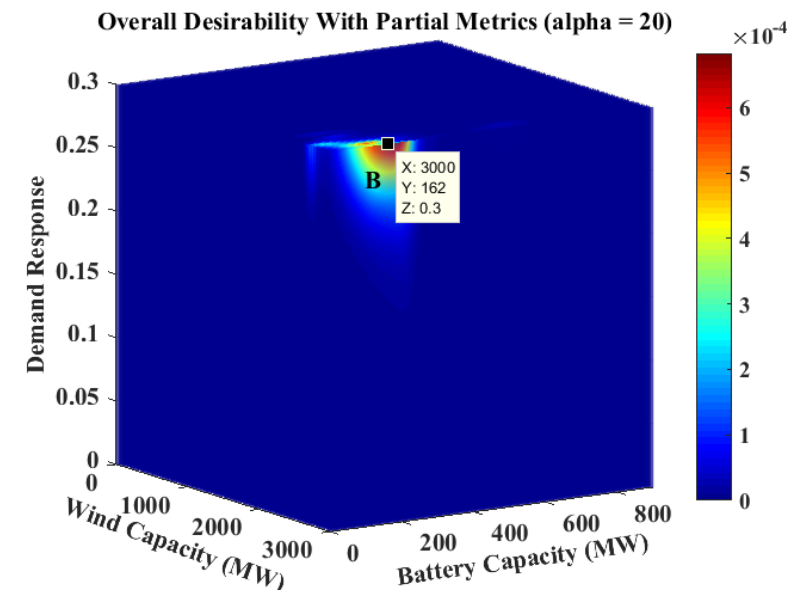

(b)

Figure 8 a) Overall desirability with all metrics, b) Overall desirability with partial metrics 
Table 1 Proposed quantitative performance metrics

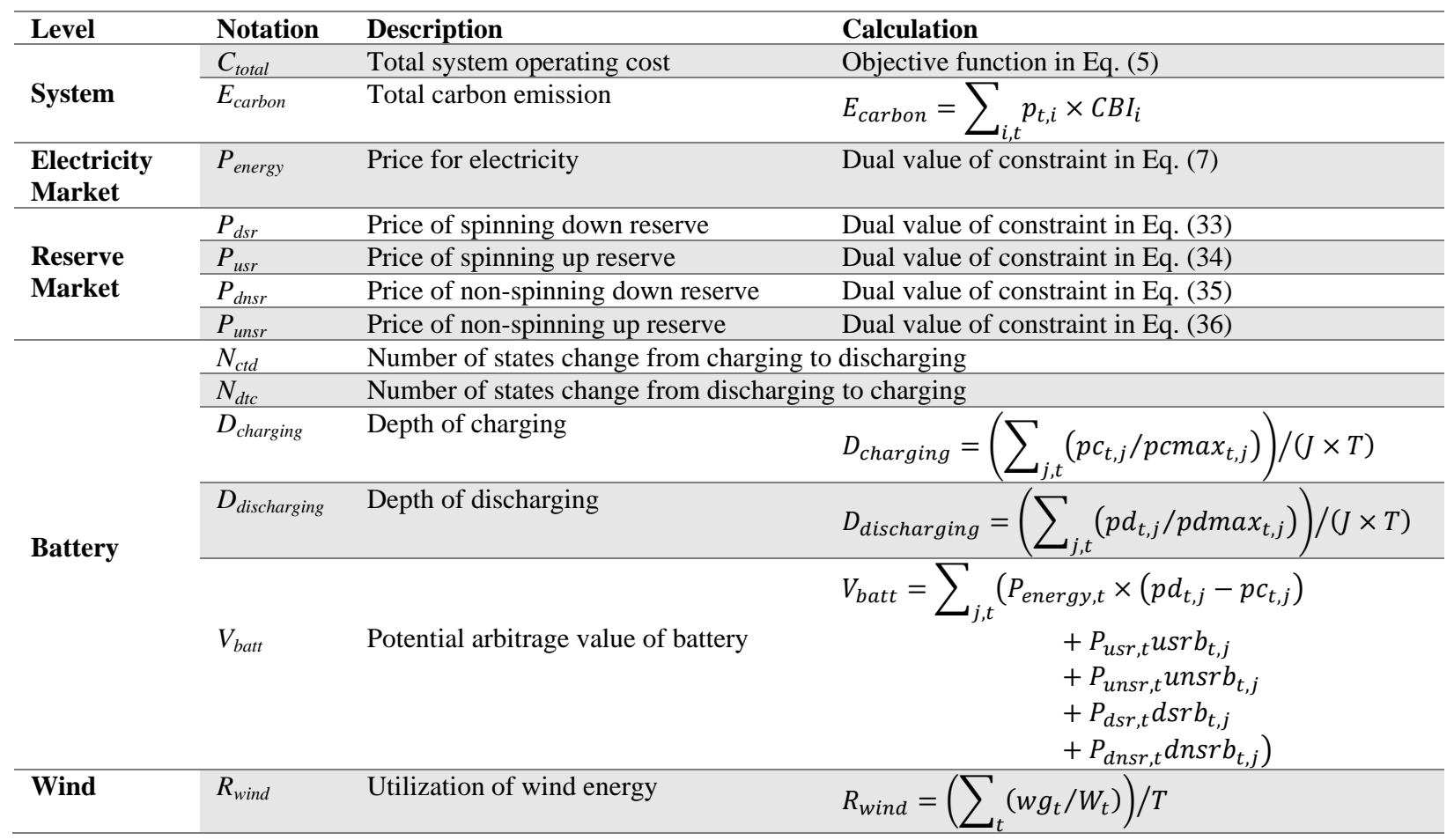


Table 2 Significance test of different emerging technologies

\begin{tabular}{|c|c|c|c|c|c|c|c|c|c|c|c|c|}
\hline & \multicolumn{2}{|c|}{ Wind } & \multicolumn{2}{|c|}{ Battery } & \multicolumn{2}{|c|}{ Demand Response } & \multicolumn{2}{|c|}{ Wind \& Battery } & \multicolumn{2}{|c|}{ Wind \& DR } & \multicolumn{2}{|c|}{ Bttery \& DR } \\
\hline & $F$ ratio & $p$-value & $F$ ratio & $p$-value & $F$ ratio & $p$-value & $F$ ratio & $p$-value & $F$ ratio & $p$-value & $F$ ratio & $p$-value \\
\hline$C_{\text {total }}$ & 1689.070 & $<.0001 *$ & 188.3223 & $<.0001^{*}$ & 351968.2 & $<.0001^{*}$ & 85.3644 & $<.0001 *$ & 4.0959 & $0.0439 *$ & 6.0973 & $0.0141 *$ \\
\hline$E_{\text {carbon }}$ & 72245.45 & $<.0001^{*}$ & 109.6541 & $<.0001 *$ & 19.2458 & $<.0001 *$ & 127.7851 & $<.0001 *$ & 0.0194 & 0.8893 & 0.1623 & 0.6874 \\
\hline$P_{\text {energy }}$ & 34.3327 & $<.0001 *$ & 76.6454 & $<.0001^{*}$ & 1.5640 & 0.2121 & 48.2845 & $<.0001 *$ & 3.1800 & 0.0756 & 7.8480 & 0.0054* \\
\hline$P_{u s r}$ & 37.3206 & $<.0001^{*}$ & 19.5269 & $<.0001^{*}$ & 11.9868 & $0.0006^{*}$ & 22.9369 & $<.0001^{*}$ & 0.9082 & 0.3414 & 3.1802 & 0.0756 \\
\hline$P_{\text {unsr }}$ & 0.0397 & 0.8421 & 0.0092 & 0.9235 & 0.0073 & 0.9322 & 0.6137 & 0.4340 & 0.7691 & 0.3812 & 0.7469 & 0.3882 \\
\hline$P_{d s r}$ & 65.9506 & $<.0001 *$ & 77.4448 & $<.0001 *$ & 3.8629 & 0.0503 & 111.9403 & $<.0001 *$ & 6.2253 & $0.0131 *$ & 11.0257 & $0.0010^{*}$ \\
\hline$P_{d n s r}$ & 71.0323 & $<.0001^{*}$ & 49.5749 & $<.0001^{*}$ & 5.2938 & $0.0221^{*}$ & 77.7921 & $<.0001^{*}$ & 11.8022 & $0.0007^{*}$ & 10.1066 & $0.0016^{*}$ \\
\hline$D_{\text {char }}$ & 5.1041 & $0.0246^{*}$ & 1.2646 & 0.2617 & 2.8315 & 0.0935 & 24.8171 & $<.0001^{*}$ & 0.0865 & 0.7689 & 0.4442 & 0.5056 \\
\hline$D_{\text {discharging }}$ & 19.3819 & $<.0001 *$ & 373.8676 & $<.0001^{*}$ & 4.4574 & $0.0356^{*}$ & 0.6087 & 0.4359 & 1.2943 & 0.2562 & 2.4322 & 0.1199 \\
\hline$N_{c t d}$ & 15.4897 & $0.0001 *$ & 367.8378 & $<.0001^{*}$ & 0.2379 & 0.6261 & 0.0492 & 0.8245 & 2.5422 & 0.1119 & 0.9807 & 0.3229 \\
\hline$N_{d t c}$ & 137.5585 & $<.0001^{*}$ & 48.2349 & $<.0001 *$ & 3.0020 & 0.0842 & 14.4893 & $0.0002^{*}$ & 0.1782 & 0.6732 & 0.2891 & 0.5912 \\
\hline$V_{\text {batt }}$ & 112.2145 & $<.0001 *$ & 45.0344 & $<.0001^{*}$ & 4.4602 & $0.0355^{*}$ & 88.4019 & $<.0001 *$ & 3.7133 & 0.0549 & 0.4065 & 0.5243 \\
\hline$R_{\text {wind }}$ & 0.4916 & 0.4838 & 7.0442 & $0.0084 *$ & 0.0192 & 0.8899 & 4.1991 & $0.0413 *$ & 0.1119 & 0.7382 & 0.0176 & 0.8945 \\
\hline
\end{tabular}


Table 3 Evaluation of various data-driven models for each performance metric using NRMSE values

\begin{tabular}{|c|c|c|c|c|c|c|c|c|}
\hline $\begin{array}{c}\text { Performance } \\
\text { Metrics }\end{array}$ & $\mathbf{R B F}^{\mathbf{a}}$ & KRIG $^{\mathrm{b}}$ & POLY ${ }^{\mathrm{c}}$ & MARS $^{\mathbf{d}}$ & $\begin{array}{l}\text { MIX } \\
\text { RcM }^{\text {e }}\end{array}$ & $\begin{array}{l}\text { MIX } \\
\operatorname{RcPc}^{f}\end{array}$ & $\underset{\text { KgPc }^{\mathrm{MIX}}}{\operatorname{Min}}$ & $\begin{array}{c}\text { MIX } \\
\text { RcKgM }^{\mathrm{h}}\end{array}$ \\
\hline$C_{\text {total }}$ & 0.0029 & 0.0018 & 0.0062 & 0.0083 & 0.0034 & 0.0030 & 0.0024 & 0.0024 \\
\hline$E_{\text {carbon }}$ & 0.0053 & 0.0059 & 0.0139 & 0.0192 & 0.0065 & 0.0062 & 0.0075 & 0.0065 \\
\hline$P_{\text {energy }}$ & 0.0636 & 0.0747 & 0.0537 & 0.0672 & 0.0540 & 0.0513 & 0.0653 & 0.0584 \\
\hline$P_{u s r}$ & 0.1485 & 0.0914 & 0.0915 & 0.1048 & 0.1122 & 0.1145 & 0.0922 & 0.0943 \\
\hline$P_{\text {unsr }}$ & 0.2686 & 0.1688 & 0.1529 & 0.1624 & 0.2281 & 0.2363 & 0.1646 & 0.1665 \\
\hline$P_{d s r}$ & 0.0507 & 0.0311 & 0.0638 & 0.0988 & 0.0523 & 0.0442 & 0.0377 & 0.0379 \\
\hline$P_{d n s r}$ & 0.0702 & 0.0736 & 0.0619 & 0.0898 & 0.0643 & 0.0541 & 0.0674 & 0.0617 \\
\hline$D_{\text {charging }}$ & 0.0993 & 0.0640 & 0.0612 & 0.0720 & 0.0825 & 0.0838 & 0.0638 & 0.0670 \\
\hline$D_{\text {discharging }}$ & 0.0771 & 0.0612 & 0.0503 & 0.0590 & 0.0622 & 0.0633 & 0.0566 & 0.0585 \\
\hline$N_{c t d}$ & 0.0915 & 0.0757 & 0.0692 & 0.0792 & 0.0762 & 0.0757 & 0.0739 & 0.0725 \\
\hline$N_{d t c}$ & 0.1058 & 0.0766 & 0.0708 & 0.0898 & 0.0865 & 0.0847 & 0.0753 & 0.0793 \\
\hline$V_{\text {batt }}$ & 0.1016 & 0.0819 & 0.0944 & 0.1234 & 0.0903 & 0.0824 & 0.0828 & 0.0774 \\
\hline$R_{\text {wind }}$ & 0.0596 & 0.0679 & 0.0578 & 0.0697 & 0.0612 & 0.0594 & 0.0629 & 0.0607 \\
\hline
\end{tabular}

${ }^{a}$ Cubic radial basis function interpolant. ${ }^{b}$ Kriging model with Gaussian correlation function and second order regression polynomial. ${ }^{\mathrm{c}}$ Cubic regression polynomial. ${ }^{\mathrm{d}}$ Multivariate adaptive regression spline. ${ }^{\mathrm{e}}$ Mixture of cubic radial basis function interpolant and multivariate adaptive regression spline. ${ }^{\mathrm{f}}$ Mixture of cubic radial basis function interpolant and cubic regression polynomial. ${ }^{\mathrm{g}}$ Mixture of kriging model with Gaussian correlation function (second order regression polynomial) and cubic regression polynomial. ${ }^{\mathrm{h}}$ Mixture of cubic radial basis function interpolant, Kriging model with Gaussian correlation function (second order regression polynomial) and multivariate adaptive regression spline. 
Table 4 Desirability for all performance metrics at point A and B

\begin{tabular}{ccc}
\hline Desirability & Point A & Point B \\
\hline$C_{\text {total }}$ & 0.792 & 0.970 \\
\hline$E_{\text {carbon }}$ & 0.963 & 0.888 \\
\hline$P_{\text {energy }}$ & 0.351 & 0.527 \\
\hline$P_{d s r}$ & 0.925 & - \\
\hline$P_{u s r}$ & 0.776 & - \\
\hline$P_{\text {dnsr }}$ & 0.941 & - \\
\hline$P_{\text {unsr }}$ & 0.806 & - \\
\hline$N_{\text {ctd }}$ & 0.311 & - \\
\hline$N_{\text {dtc }}$ & 0.720 & - \\
\hline$D_{\text {charging }}$ & 0.715 & - \\
\hline$D_{\text {discharging }}$ & 0.323 & 0.827 \\
\hline$V_{\text {batt }}$ & 0.296 & 0.431 \\
\hline$R_{\text {wind }}$ & 0.567 & 0.695
\end{tabular}

